\title{
Elicitation Requirements
}

This chapter discusses the elicitation in work process design and its requirements on socio-technical support instruments. It provides the conceptual underpinnings of the articulation and alignment processes occurring during work process elicitation, drawing from different disciplines such as social psychology, cognitive sciences, knowledge management, and computer-supported collaborative work. We finally offer a theory-based synthesis of the concepts developed in these areas to inform and reflect on the methods' design in the following chapters.

Although a thorough acquisition of work knowledge is almost never readily available for development, requirements can be identified on how information could be articulated and aligned for further processing, both, in terms of elicitation, and representation, as well as inherent conditions and support. Much of the adjacent methodological and technological requirements are not documented - they reside in the minds of experienced developers or stakeholders concerned with organizational design. Although requirements for system design need to be elicited or drawn out, the methodology on how to thoroughly identify the stakeholder capabilities, needs, risks, and assumptions associated with a given work setting, business, or project is unclear in most cases. 
In the following, we start with an individual perspective on elicitation and call for role awareness in this process, as work processes can be distinguished at least by functional roles individual actors need to take in order to achieve business objectives. Understanding one's own role(s) lays the ground to adopt various perspectives on work procedures and consider context relevant for role-specific behavior. The resulting situatedness enables reflecting on the scope of work tasks and re-shaping organizational structures in collaborative settings. In order to handle complex situations, a systems-of-system perspective could help. Bringing intangible or implicit knowledge to the surface and to represent it qualifies for aligning mental models on existing work procedures and behaviors in a comprehensive way. It facilitates co-creating future work settings, in particular, taking into account the continuous penetration of digital systems into work task accomplishment.

\subsection{Setting the Stage-Awareness on Roles and Their Management}

Traditionally, the preparation for elicitation is the first step. It aims towards a comprehensive and an accurate understanding of the work situation and the needs of involved stakeholders. During the elicitation process, an analyst's understanding of the work needs helps in scoping and selecting proper stakeholders and elicitation techniques. Hence, stakeholders need to get actively engaged in articulation and alignment. Stakeholders here are understood as any persons that are directly or indirectly affected by a work process or engage in it. This may include customers/end users, suppliers, the project manager, quality assurance, regulators, business partners, operational support, domain subject matter experts, and implementation specialists.

A facilitator needs to recruit appropriate stakeholders based on the intended project or scope of activities. After a facilitator has identified and recruited relevant stakeholders, before $\operatorname{method}(s)$ by which elicitation can be performed, it is advisable to create awareness on roles and role identities, in particular due to the proliferation of digital media and their social media capabilities: 
New communication technologies have freed interaction from the requirements of physical copresence; these technologies have expanded the array of generalized others contributing to the construction of the self. Several research foci emerge from this development: the substance of 'I', 'me', and the generalized other in a milieu void of place, the establishment of 'communities of the mind', and the negotiation of copresent and cyberspace identities. (Cerulo 1997, p. 386)

Consequently, not only at the workplace, but also in all of today's societal communities, stakeholders have had to learn dealing with a variety of roles. They can present themselves differently based on who they are talking to and what an interaction is about (cf. Castells 1997). When using content management systems or social media to share their experiences with work processes, they act in a certain role. The role is based on technological affordances and immediate context. Roles may either be described in certain profiles using registration wizards, or recorded along the interaction, for example, documenting paths in business information systems.

The first case might be obvious for role design and presenting oneself, whereas the latter most of us become aware of once receiving own behavior data, for example, when having searched for information and receiving proposals referring to our search pattern. Hence, role design and management have become increasingly important when multiple situation elements occur in some concerted manner. Consider, for instance, searching for information on a product in an online catalogue. The user could be a novice in product management or customer service. It could also be an experienced product manager or a barely skilled customer agent. Role types occur along various dimensions and domains, such as level of skill with respect to features or technologies, and expertise in a domain. They need to be recognized for articulating and aligning work knowledge, in particular when involving multiple technical communities, as our exemplified user may also ask questions in a product forum in which authors address novice workers (cf. Ellison et al. 2006).

If stakeholders are more aware about their content creation and usage as well as communication acts, their role in interaction becomes more transparent to them, and they are able to articulate their knowledge in a more reflected way. It has been observed that people react to situations based on context rather than fixed behavior patterns (cf. Meyrowitz 1986). In our 
example, all three items, that is, the level of competence in product handling, searching with descriptors and meta-data, and interactive navigation have to be considered in their mutual context.

In an information-based-and yet more important, in a knowledgebased-work environment, roles are functional entities based on the stakeholder identities, evolving over time (Castells 1997). Their management goes beyond traditional presentation formats, such as yellow page entries or personal web pages, as stakeholders are acting in various roles in dynamically changing (virtual) communities (cf. Jensen Schau and Gilly 2003). Virtual communities in the knowledge age society are groups of people connected via social and knowledge media. They engage in knowledge creation, documentation, sharing, collective use, and distribution.

Community members take the role of content providers, explorers, and respondents. They may change these roles dynamically, driven by their personal identities triggering their behavior (cf. Montague 2013; Ackerman et al. 2017). Such static descriptions of the Self are more structured than blogs and information boards, presuming ongoing interactions among community members (Robinson 2007). However, in virtual communities, goal-oriented interaction forms the awareness of its members and finally, their individual activities (Ellison et al. 2006).

Meyrowitz (1986) has already observed that social media tend to blur the lines between 'front stage' (what should be visible) and 'back stage' behaviors (what currently is not, but potentially should, become visible to others). Consequently, facilitators and analysts need to look at dealing with the 'front' and 'back' stage dynamically. Bridges are the features of new media, in particular, when operating under the control of stakeholders. Context thus becomes paramount in a virtual community, and the role of management within it (Ferscha et al. 2004a). However, selfregulated role management seems to be a challenging task. Jarvis (2009) and Jarvis and Watts (2012) indicate that role management is a learning task, as becoming a self in society, both mind and self are socially learned phenomena. It has to deal with informed learning activities and might include conflicting individual and social interests.

Although roles can be part of various contexts, they constitute the appearance of individual actors. Even when related to learning how to 

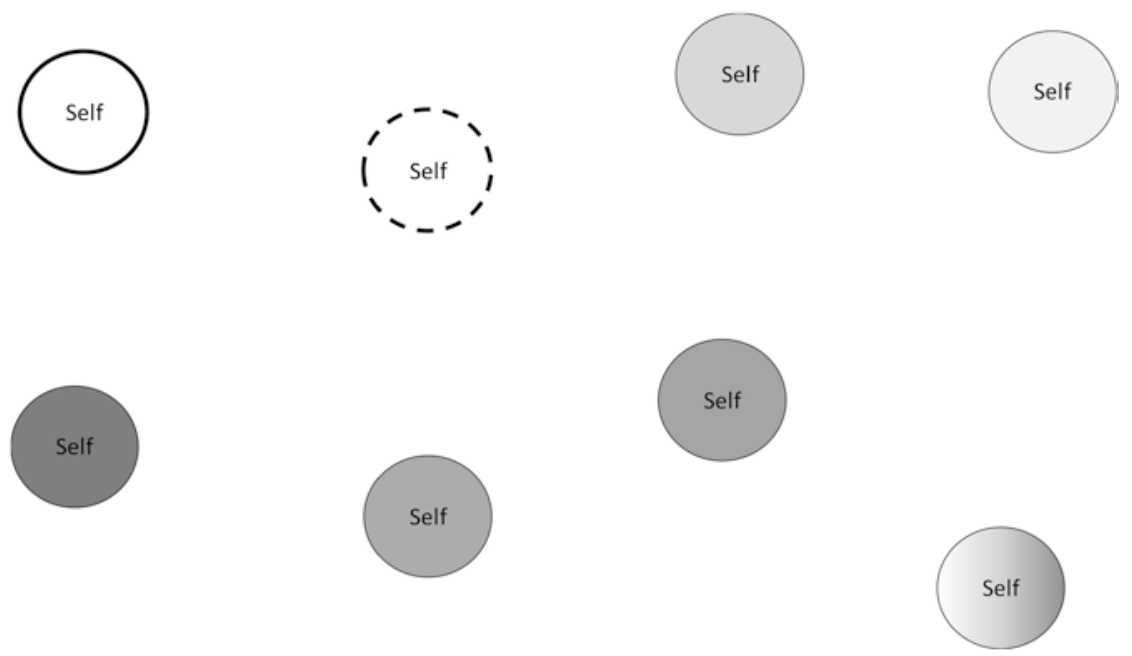

Fig. 2.1 Awareness on roles

manage various roles, their set up is relevant to how stakeholders get involved in work knowledge elicitation. Consequently, articulation support requires features for stakeholders to make roles transparent, if not build capacity to manage them in a reflected and structured way.

Figure 2.1 visualizes setting the stage in terms of identifying one's role. Self denotes an actor who has a certain role. Different Selfs are represented by different colors or tones. The roles are pictured by the surrounding circles. As shown in the figure, actors can play different roles - the Self with the white background has two roles, which is denoted by different outlines of the circle.

\subsection{Situation Awareness}

As already mentioned above, the development of organizations, and thus socio-technical systems, is increasingly driven by its members. Hence, stakeholders need to spend socio-cognitive effort when articulating and aligning knowledge about their work. Role- and task-specific behavior of stakeholders is framed by its triggers, such as individual intention, and its expected effects or outcome. This framing can be done on arbitrary levels 
of granularity, depending on a stakeholder's perspective and/or level of competence or insight. Elicitation, modeling, and probing should be guided by direct recall, avoiding errors, incompatibilities, and inconsistencies grounded in articulation and representation (Harman et al. 2015).

Such recalls require insight into the situations that stakeholders face or are part of when accomplishing tasks. They lay the ground for situated articulation and allow framing activities with situation-specific information, both on triggering them, and on effectuation (cf. Gross et al. 2005). Triggers can be events (externally set) or intentions (stakeholder-specific) in combination with input data to be processed, whereas effectuation is represented through output in terms of data or states, and the outcome, that is, the (intended) effect of a certain activity or a set of actions.

The most authentic articulation and representation of situations can be assumed to stem from stakeholders experiencing these situations. In selfcontained articulation settings, stakeholders do not have to rely on information provided by analysts, in contrast to settings involving external people, such as for interviewing, where it cannot be assumed that analysts or facilitators are familiar with the field (Parsaye and Chignell 1988). Moreover, stakeholders, in particular experts, when asked explicitly, forget to mention tasks they assume to be widely known, or have difficulties explaining what they do when not actually doing it at the same time (Grosskopf et al. 2010). Knowledge is thus inseparable from doing (cf. Brey 2005).

Putting situated cognition theory in the context of representation, generated models in a natural and intuitive way potentially have greater accuracy than what could traditionally be achieved with common acquisition and analysis techniques (cf. Harman et al. 2015). Reducing the requirement of involving external people enables a wider scope of selforganizing work, as many more stakeholders can participate in organizational change and development.

An underlying concept in this context seems to be 'agency.' According to Himma (2009),

[the] idea of agency is conceptually associated with the idea of being capable of doing something that counts as an act or action. As a conceptual matter, $\mathrm{X}$ is an agent if and only if $\mathrm{X}$ is capable of performing action; breathing is something we do, but it does not count as an action. Typing these words is an action, and it is in virtue of my ability to do this kind of thing 
that, as a conceptual matter, I am an agent. ... Agents are not merely capable of performing acts; they inevitably perform them (in the relevant sense). ... The very concept of agency presupposes that agents are conscious. (p. 19)

Reflecting this understanding reveals the way of involvement in a situation when humans are acting or interacting. It underpins the requirement to devote design effort to human issues to the same extent developers spend for technical ones. The recognition of user modeling can be considered such an endeavor (cf. Brusilovsky and Cooper 2002). Situatedness is awareness about its world, comprising communities, organizations, societies, or other contingent systems of systems, and its capability to induce changes on it (cf. Campos et al. 2009).

The essence of situation awareness lies in the monitoring of various entities and the relations that occur among them. Since the properties of relations, unlike the properties of objects, are not directly measurable, one needs to have some background knowledge (such as ontologies and rules) to specify how to derive the existence and meaning of particular relations. (Matheus et al. 2005)

Consequently, system development, concerning cognition, organizations, social or technological systems, should be driven by different systemic perspectives and lead to architectures allowing dynamic changes (cf. Rolland et al. 1999). Situatedness of development processes is a key issue in software and method engineering communities (cf. Barwise and Perry 1981). Prescriptions, from either the user interaction or the task handling perspective, need to be adapted to the situation at hand, allowing for systems dynamics in the course of task or interaction processes (Christian Stary 2017a).

According to findings in cognitive science, actors (there referred to as 'agents') are considered as embodied and interactively situated in worlds (Dobbyn and Stuart 2003). When analyzing the meanings attached to these terms a set of conditions for situatedness and embodiment can be derived, based on the conclusive assumption that external representational schemes are required for adaptation. While virtual agents in virtual worlds are considered neither situated nor embodied, awareness of evolving goals, various modalities for interaction and task accomplishment procedures could lead to a rich repertoire of interactions (cf. Gross et al. 2005). 
Embedded actors could develop individual points of view, relative to their starting position work spaces, and have a capacity to develop a dedicated interaction space. None of these capabilities are possible without representation of work activities. They can either rely on engineering work flows, as for example, in Business Process Management (Weske 2010), or on engineering of cognitive support, such as model-based approaches (cf. Christian Stary 2000). The latter need to relate to cognitive constructs (cf. Eberle et al. 2011). Thereby, mutual relationships between user properties and interaction styles can be captured in terms of cognitive characteristics. In addition, rules for dynamically tuning task accomplishment and interaction can be kept in dedicated representation schemes, such as adaptation models.

The problem with this type of context information is that it cannot be encoded with standardized approaches, such as BPMN (Business Process Modeling Notation; www.bpmn.org). While an expert may be able to explain the rationale for work activities, these normative representations do not convey required context to information (cf. Brown et al. 1989). Hence, additional effort is required to provide adequate context information, for example, through apprenticeships (Lave 1988). From this, theories of explicit memory, sometimes referred to as tacit knowledge, have emerged, as knowledge cannot easily be conveyed to other people. To retrieve this information, it is easiest to use a simulation-based approach for memory recall (Rubin 2006).

For articulating context when capturing role- or task-specific work knowledge, activity-relevant information can be framed in a structured way (cf. Christian Stary 2017b). As shown in Fig. 2.2, a tripartite approach could consist of:

\begin{tabular}{|l|c|l|}
\hline \multirow{2}{*}{ Intention and/or event } & $\begin{array}{c}\text { In my role as } \\
<\text { (functional) actor > } \\
\text { I perform } \\
\text { input }\end{array}$ & Outcome \\
\cline { 1 - 1 } & < set of actions > & Output \\
& & \\
\hline
\end{tabular}

Fig. 2.2 The articulation scheme containing trigger, role-specific activity, and effect 
1. Trigger and incoming information: Hereby we distinguish pragmatically and semantically relevant information (context) from syntactic structure (input). At least the context should be given when a task chain is started.

2. Functional processing information: It specifies not only the function in terms of activities to be set, but rather the role in which a work task is performed. In this way, the context can be represented more accurately compared with purely functional specifications.

3. Effect and deliverables: Again, we distinguish pragmatically and semantically relevant information (outcome denoting the effect of using a feature) from the syntactic structure (output). At least some outcome should be generated once a work task chain is completed.

For each task-relevant behavior, a separate representation could be generated by stakeholders in the course of eliciting work knowledge (cf. Christian Stary 2017d).

Framing of role-specific actions by triggering and effectuating behavior allows for scoping actor behaviors, as the following example demonstrates. A service provider in the field of software development has a stakeholder in the functional role of a Customer Service Agent who articulates how a product claim from a customer is framed. The input is a product claim, for example, when a product does not meet a customer requirement. The intention is to help the concerned customer, until he/ she is satisfied. The output of this activity is either a hint about how the requirement has already been met, or a change request for product development, in case it could not be met so far (Fig. 2.3).

From a work process perspective, this representation constitutes a particular actor with behavior. Although in the course of articulation, the

\begin{tabular}{|l|l|l|}
\hline Help customer & $\begin{array}{l}\text { In my role as Customer } \\
\text { Service Agent I handle } \\
\text { a product claim. }\end{array}$ & Customer is satisfied \\
\cline { 3 - 3 } Product claim & Hint to change request \\
\hline
\end{tabular}

Fig. 2.3 Customer service actor behavior handling customer product claims 


\begin{tabular}{|l|l|l|}
\hline Innovate product & $\begin{array}{l}\text { In my role as } \\
\text { Customer Service } \\
\text { Agent I re-formulated }\end{array}$ & Product changes \\
\cline { 1 - 3 } $\begin{array}{l}\text { Product claim from } \\
\text { customer }\end{array}$ & Idea ticket \\
\hline & $\begin{array}{l}\text { The product claim } \\
\text { Towards innovative featuring }\end{array}$ & \\
\hline
\end{tabular}

Fig. 2.4 Scoping another actor behavior-Idea Provider

functional role (Customer Service Agent) provides an intuitive entry point, the label could more accurately read 'product claim customer handling', as it is very likely that the work agenda of the Customer Service Agent comprises additional actions.

In case the Customer Service Agent reports in constructive way and has an idea for innovating the product based on product claims or customer requests, the articulation scheme enables switching the role in that context. Figure 2.4 shows a coherent representation for that case.

The consequences for work process modeling are substantial, since handling a product claim as a 'Customer Service Agent' shapes an actor taking a functional role, communicating with the customer, and product department. A particular role-'Idea Provider'-allows not only in reducing the complexity when the workplace of a service agent is described, but rather enables developing a product improvement or organizational learning procedure that could serve as a pattern across organizational units or domains.

The latter model could serve as input for the change manager to implement product innovation processes after the proposal has been collectively reflected on. For a complete task chain, and thus business process specification, each output of an activity needs to correspond to an input of an adjacent activity.

Procedural requirements. When framing role- or task-specific behavior in the way described above, contextual representations need to be set up along a procedure allowing to articulate intentions. Grice (1969) has already investigated the relationship between meaning and intention of 
utterers. From Böhm (1997)'s research, we can conclude that meaning constitutes sense-making for humans, as it needs to be seen intertwined with the functional context of a person and the goals this person is trying to achieve individually (ibid., p. 69).

Sheeran (2002) has studied possible gaps between behavior and intention. Looking for psychological variables to 'bridge' possible intentionbehavior gaps, the author's meta-analysis of meta-analyses has led to a conceptualization of intention-behavior discrepancies. Four groups of variables, namely behavior type, intention type, properties of intention, and cognitive and personality variables, could be clustered as they moderate intention-behavior relations. Once behavior specifications contain a task description according to individual mental models, any verbalization of intention respects the stakeholder's personality and the cognitive model of a situation. As the intention type is not essential when articulating triggers of actions, each stakeholder can describe the way he/she perceives it in the intentional context of the action (set) at hand.

Hug et al. (2012) have referred to intentions in the context of process engineering. Rather than detailing how to facilitate stakeholder articulation with respect to intentional behavior, "the intentional level is used to guide engineers through IS [Information Systems] processes by dynamic choices. Each time an intention is achieved the model suggests the next steps that can be enacted and new ways to achieve them. The resulting IS development process is adaptive and flexible as it is dynamically constructed" (ibid., p. 204). As we will see below, for establishing intentional fit of activities, this input is valuable.

The presented sample scheme should illustrate how behavior could be captured in a context-rich way when articulating knowledge on work tasks. The scheme frames activities by triggers (incoming side) and intended effects (outgoing side). As such, activities can be contextualized with situation-specific information.

Figure 2.5 visualizes situation-awareness of actors in specific roles. The Self denotes an actor who plays a certain role in a certain situation. The role is pictured by the surrounding circle, whereas the situation context is denoted by a dotted cloud symbol. As shown in the figure, actors can not only play different roles, but also act in a certain role in different situations - the Self with the white background has two roles (denoted by 

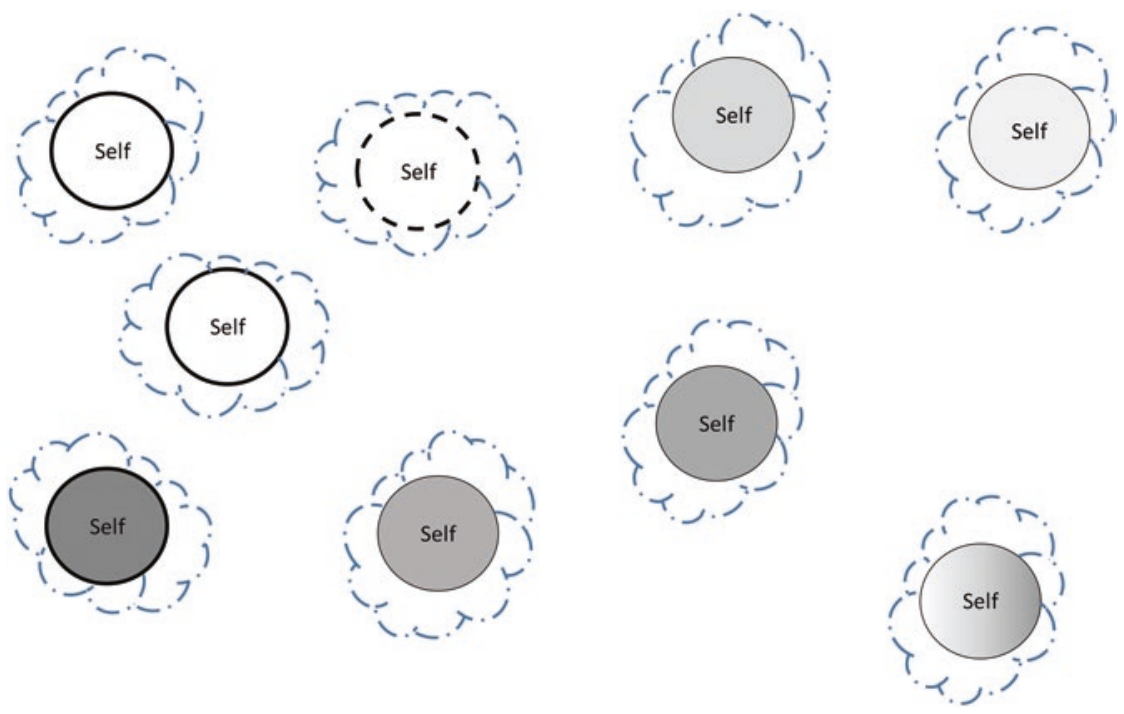

Fig. 2.5 Situation awareness

different shapes of the circle), with one role (the one with the solid circle in the figure) considered relevant for two different situations.

\subsection{Conceptual Understanding of Complex Systems}

The advent of digital transformation invading all societal and economic systems requires a re-consideration of the generative nature of sociotechnical system design. In particular, this transformation needs be studied with regard to how links are continuously explored and accelerated between existing as well new value spaces (Bounfour 2016). The accelerated production of relations does not only substantiate system thinking (cf. Senge 1990; Senge and Sterman 1992), but also characterizes the fundamental nature of digital production systems - relations are considered essential drivers for creating value in digital spaces (Bounfour 2016). We need to delineate their nature, as being transactional, organic, or semi-organic, since they lead to deep changes in the way we 'produce', 
and finally affect business models and power relations of organizations and societies (ibid.).

As digital transformations are complex, some scholars have already called for a system science approach to deal with these challenges (Flood and Carson 2013). Thereby, traditional cognitive or top-down approaches to regulate or control dynamic processes are seen as a 'last resort' (Colander and Kupers 2014). Evolving complex systems bear systemic challenges (ibid.), which are wicked due to their social or cultural nature and incomplete, contradictory, interconnected, and changing requirements that are often difficult to recognize. Bringing together complexity and wicked problem theories to understand how individual organizations and change agents can better influence large system change, Waddock et al. (2015) developed a respective framework. It integrates wicked problems and complexity theories to cope with large systems interventions while taking the perspective of individual change agents. Although the authors concluded their study that change agents in organizations can enhance their influence and use the power of system dynamics to support positive action for sustainable change, they recognized that effective large-scale change still has limited theoretical understanding.

Consequently, not only do we need to put forward theoretical understanding of change management by positioning the organization in the context of a broader system, but we also need to define its role in creating change based on articulation of individual stakeholders (cf. Senge's perspective on a learning organization requiring learning members of that organization). Individually informed articulation (e.g., on principles for acting) is likely to facilitate addressing the nature of wicked problems by setting informed relations between individual systems and the large systems where they are embedded.

Accepting the wickedness of challenges and complex problems, we need to shed light on the relation of individuals as change agents and their relations to organizations and society in transformational change. These transformations can be substantial and lead to emerging individual and social behaviors due to that change. Research reveals the essential role of individuals when structuring situated cognitive transformation processes (Kihlstrom 2013): 
Evocation, selection, and manipulation all change the environment through overt behavior - either the behavior of the person him- or herself, or that of other people. In each case, someone does something overtly that changes the objective character of the environment-that is, changes the environment for everyone in it, not just for the person itself. But these three modes do not exhaust the effects of the person on the environment. People also engage in covert mental activities that alter their mental representations of their subjective environment - that is, the environment as they privately experience it. As opposed to behavioral manipulation, cognitive transformation does not act directly on the objective environment-the environment as it would be described in the third person by an objective observer and experienced by everyone in it. Rather, transformation acts on the subjective environment. Through cognitive transformations, people can change their internal, mental representations of the external physical and social environment-perceiving it differently, categorizing it differently, giving it a different meaning than before. In cognitive transformation, the objective features of the environment remain intact-they have not been altered through evocation, selection, and manipulation. Rather, the cognitive transformation has altered the environment for that person only. The environment is unchanged for everyone else-unless and until the cognitive transformation leads the person to engage in selective and manipulative behavior that, as described earlier, will change the environment for everyone in it. (Kihlstrom 2013, p. 798)

We cannot foresee how the various systems will act, and deal with traditional mechanisms to organize and control. We need to assume anarchic patterns, questioning traditional authority or other controlling systems.

One way to deal with the social dimensions of organizations and the resulting dynamics of systems involving embodied stakeholders is to take a Complex Adaptive Systems (CAS) perspective. According to Chan (2001), CAS started in US to oppose the European 'natural science' tradition in the area of cybernetics and systems. Although CAS theory shares the subject of general properties of complex systems across traditional disciplinary boundaries (like in cybernetics and systems), it relies on computer simulations as a research tool (as pointed out by Holland in 1992 initially (Holland 1992)), and considers less integrated or 'orga- 
nized' systems, such as ecologies, in contrast to organisms, machines, or enterprises. Many artificial systems are characterized by apparently complex behaviors due to often non-linear spatio-temporal interactions among a large number of component systems at different levels of organization; they have been termed Complex Adaptive Systems (CAS).

CAS are dynamic systems able to adapt in and evolve with a changing environment. It is important to realize that there is no separation between a system and its environment in the idea that a system always adapts to a changing environment. Rather, the concept to be examined is that of a system closely linked with all other related systems making up an ecosystem. Within such a context, change needs to be seen in terms of coevolution with all other related systems, rather than as adaptation to a separate and distinct environment (Chan 2001, p. 2). CAS have several constituent properties (ibid., p. 3ff):

- Distributed control: There is no single centralized control mechanism that governs system behavior. Although the interrelationships between elements of the system produce coherence, the overall behavior usually cannot be explained merely as the sum of individual parts.

- Connectivity: A system does not only consist of relations between its elements, but also of relations with its environment. Consequently, a decision or action by one part within a system influences all other related parts.

- Co-evolution: With co-evolution, elements in a system can change based on their interactions with one another and with the environment. Additionally, patterns of behavior can change over time.

- Sensitive dependence on initial conditions: CAS are sensitive due to their dependence on initial conditions. Changes in the input characteristics or rules are not correlated in a linear fashion with outcomes. Small changes can have a surprisingly profound impact on overall behavior, or vice-versa, a huge upset to the system may not affect it. ... This means the end of scientific certainty, which is a property of 'simple' systems (e.g., the ones used for electric lights, motors, and electronic devices). Consequently, socio-technical systems are fundamentally unpredictable in their behavior. Long-term prediction and control are therefore believed to not be possible in complex systems. 
- Emergent order: Complexity in CAS refers to the potential for emergent behavior in complex and unpredictable phenomena. Once systems are not in equilibrium they tend to create different structures and new patterns of relationships. CAS function best when they combine order and chaos in an appropriate measure-this phenomenon has been termed Far from Equilibrium. CAS in their dynamics combine order and chaos, and thus, stability and instability, competition and cooperation, order and disorder-being termed the State of Paradox.

A complex socio-technical system is a group of different types of elements (i.e., related nodes of a network), existing far from equilibrium, when forming interdependent, dynamic evolutionary networks that are sensitive dependent and fractionally organized (Fichter et al. 2010). Taking a CAS perspective requires system thinking in terms of networked but modular elements acting in parallel (Holland 2006). In socio-technical settings, these elements can be individuals, technical systems or their features. Understood as CAS, they form and use internal models to anticipate the future, basing current actions on expected outcomes. It is this attribute that distinguishes CAS from other kinds of complex systems; it is also this attribute that makes the emergent behavior of CAS intricate and difficult to understand (Holland 1992, p. 24).

According to CAS theory, in CAS settings each element sends and receives signals in parallel, as the setting is constituted by each element's interactions with other elements. Actions are triggered upon other elements' signals. In this way, each element also adapts and thus, evolves through changes over time. Self-regulation and self-management have become crucial assets in dynamically changing socio-technical settings, such as organizations (Allee 2009; Firestone and McElroy 2003). Selforganization of concerned stakeholders as system elements is considered key in handling requirements for change. However, for self-organization to happen, stakeholders need to have access to relevant information of a situation. Since the behavior of autonomous stakeholders cannot be predicted, a structured process is required to guide 
behavior management according to the understanding of stakeholders and their capabilities to change their situation individually (Allee 2009; Christian Stary 2014).

From the interaction of the individual system elements arises some kind of global property or pattern, something that could not have been predicted from understanding each particular element (Chan 2001). A typical emergent phenomenon is a social media momentum stemming from the interaction of the users when deciding upon a certain behavior, such as spontaneous meetings (Ferscha et al. 2004b). Global properties result from the aggregate behavior of individual elements. Although it is still an open question how to apply CAS to engineering systems with emergent behavior (Holland 1992), in case of socio-technical system design pre-programmed behavior is a challenging task, as humans may change behavioral structures in response to external or internal stimuli. As such, stakeholders in these systems (self-)organize evolvement and adapt to a changing environment, usually generating more complexity in the process.

System-of-Systems (SoS) thinking is considered an effective way of handling CAS, in particular when developing complex artifacts in a structured way (Jamshidi 2008). According to Institute of Electrical and Electronics Engineers (IEEE's) Reliability Society, a system is “a group of interacting elements (or subsystems) having an internal structure which links them into a unified whole. The boundary of a system is to be defined, as well as the nature of the internal structure linking its elements (physical, logical, etc.). Its essential properties are autonomy, coherence, permanence, and organization" (IEEE-Reliability Society Technical Committee on Systems of Systems 2014). A System-of-Systems (SoS) is a system that involves several systems "that are operated independently but have to share the same space and somehow cooperate" (ibid., p. 2).

As such, they have several properties in common: operational and managerial independence, geographical distribution, emergent behavior, evolutionary development, and heterogeneity of constituent systems (ibid.). These properties affect setting the boundaries of $\operatorname{SoS}$ and the internal behavior of SoS, and thus, influence methodological SoS developments (Jaradat et al. 2014, p. 206). SoS are distinct with respect to: 
1. autonomy where constituent systems within SoS can operate and function independently and the capabilities of the SoS depends on this autonomy

2. belonging (integration), which implies that the constituent systems and their parts have the option to integrate to enable SoS capabilities

3. connectivity between components and their environment

4. diversity (different perspectives and functions)

5. emergence (foreseen or unexpected) (ibid.)

Several structures and categorization schemes have been used when considering complex systems as System-of Systems, ranging from close coupling (systems within systems) to loose coupling (assemblage of system). They constitute embodied systems cooperating in an interoperable way (Chris Stary and Wachholder 2016; Christian Stary 2017c; Weichhart et al. 2018), allowing for the autonomous behavior of each system while contributing through collaboration with other systems, in order to achieve the objective of the networked systems (SoS) (Maier 2005).

Referring to structural and dynamic complexity, structural complexity derives from (i) heterogeneity of components across different technological domains due to increased integration among systems and (ii) scale and dimensionality of connectivity through a large number of components (nodes) highly interconnected by dependences and interdependences. Dynamic complexity manifests through the emergence of (unexpected) system behavior in response to changes in the environmental and operational conditions of its components (IEEE-Reliability Society Technical Committee on Systems of Systems 2014).

A typical technical SoS example is contextualized apps available on a smartphone. Each of them can be considered as a system. When adjusting them along a workflow, for example, to raise alert and guide a patient to the doctor, in case certain thresholds with respect to medical conditions are reached for a specific user, several of these systems, such as the blood pressure app, calendar app, and navigation app, need to be coordinated and aligned for personal healthcare, updating the task manager of the involved users. In this case, the smartphone serves as an SoS carrier, supporting the patient-oriented redesign of the workflow, and thus, the SoS structure. The apps of the smartphone can still be used stand-alone, 

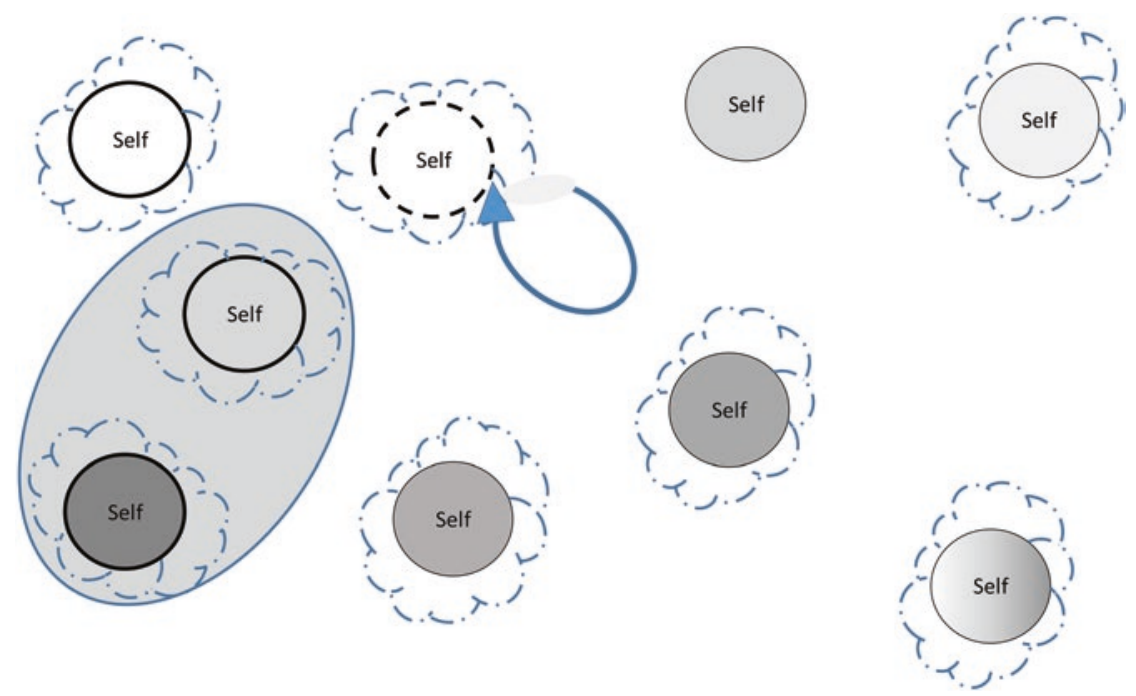

Fig. 2.6 Conceptual understanding of complex systems

while the smartphone serves as a communication infrastructure and provider of networked healthcare-relevant subsystems. It is the latter property that qualifies the smartphone as a carrier of an SoS.

When we project this concept on understanding complex organization of work, actors can become aware of their capability to act autonomously while at the same time being part of a bigger whole, namely the business organization (or even of several organizations). Figure 2.6 visualizes awareness of actors of being part of a complex systems, in this case a System-of-Systems, in their specific roles. Again, Self denotes an actor who plays a certain role (pictured by the surrounding circle) in a certain situation (denoted by a dotted cloud symbol). As shown in the figure, actors need to become aware of which System-of-Systems they are part of (they can be part of various Systems-of-Systems). In the shown case, the Self with the white background is part of a System-of-Systems consisting of two systems where the considered Self is in one role part of system one, whereas the other roles with gray backgrounds constitute the other, larger system. The second role of the Self with the white background is not part of the currently considered System-of-Systems (but might be part of other systems, which are currently out of scope for the actor reflection on being part of a complex system). 


\subsection{Creating a Reflective Practice for Situations-to-Be}

Articulation and alignment of knowledge on work processes can be directed towards reflecting work procedures (i) as they worked in the past, (ii) as they are performed now, (iii) as well as how they could work in the future. It might depend on the current work patterns of actors whose perspective is taken. However, with respect to the style of organizing work and handling work processes, Dewey distinguished impulsive and routine from reflective action (cf. Dewey 1910, 1933), since any professional behavior can have three flavors:

- Impulsive action is based on trial and error.

- Routine action is based largely on authority and tradition.

- Reflective action is based on "the active, persistent and careful consideration of any belief or supposed form of knowledge in the light of the grounds that support it" (Dewey 1933, p. 9).

Dewey explains reflective thinking as a 'chain' not only involving "a sequence of ideas but a con-sequence" of thoughts (Dewey 1933, p. 4). In his understanding, acting in open-mindedness and responsibility are consequences of reflective thinking, both facilitating developing commitment to tasks and opening for new ideas.

Schön's Reflective Practitioner approach deepens insights in reflection activities when aiming at professional capabilities to handle complex and unpredictable problems of actual practice with confidence, skill, and care (Schön 1984). A professional practitioner "can think while acting and thus respond to the uncertainty, uniqueness, and conflict involved in the situations in which professionals practice" (Adler 1991). As such, propositional knowledge is tightly coupled with know-how when instantiated in solving knowledge-intense tasks. Hence, it is the knowledge by acquaintance enabling confidence and care tackling even complex problems, which in turn requires know-how and propositional knowledge to perform tasks in a skilled way in those situations. Unique or surprising situations are handled through reframing and finding new solutions ("reflection-in-action"). This process is 
1. a conscious one, though not necessarily articulated in words

2. a critiquing one, as it leads to questions and re-structuring

3. immediately significant for action (most important) (cf. Schön 1987, p. 29)

When reviewing actions in the past rather than in-situ, "reflection-onaction" (Schön 1987) leads to evaluating already experienced situations. In case it has consequences for future action (as understood by Dewey), this reflection is transformative. Methodologically, personal narratives and autobiographies have turned out to facilitate self-exploration, in particular looking beyond or behind professional activities, such as social conditions. They allow a more comprehensive personal picture, and consequently unwrapping existing forms of Gestalt and reframing.

An andragogical premise to self-managed (co-)creation assumes the nature and characteristics of actors as maturing persons moving their selfconcepts from dependencies from surrounding systems towards selfdirectedness and autonomy in an evolving world. While experience forms the richest resource for development, readiness to act in accordance with an aligned Self is a prerequisite for (co-)creation, thus, linking task accomplishment to social behavior and endeavor (Böhm 1997).

An agogic (i.e., learning-) and situation-aware mind-set asserts that an actor's time perspective changes from postponed application of experiences and knowledge to immediacy of application and accordingly, orientation to acting shifts from subject-centered activities to focused interaction in co-creative settings (Bronfenbrenner 1981). In social settings of this kind, several agogic principles apply:

- Activities are set in accordance with the needs of participating actors under the given conditions and capabilities to act.

- Each actor has certain resources that are not only the starting point for but also the subject of design activities. These resources are accepted to be limited.

- Actors determine their way and pace of developments, as development needs to in balanced with the current conditions. Both, active participation and retreat are part of development processes.

It is the latter principle that is of crucial importance for triggering individual development and bringing it to life in a co-creative setting. 
Agogic actors need to embody (Rogers 1951; Pörtner 2008), and thus self-manage

- Empathy as sensitive understanding of others

- Appreciation of another personality without preconditioning acceptance and respect

- Congruence meaning the authenticity and coherence of one's person and behavior

The first two behaviors are based on the flow from surrounding systems to the Self, whereas congruence is decisive in making visible individual values and their attributes to other systems, and thus, part of the surrounding system. Authenticity refers to meeting a person 'as a person', to the equal of a person, experiencing a situation with the entire spectrum of channels (perceived impulses, feelings, impression, etc.). Coherence includes judging in how far or at what point in time the individual space can be shared with others, that is, becoming visible in an outer space. An essential part of congruence is that all participating actors have the same, transparent understanding of a co-creative system, including pre-set conditions and irreversible process design, for example, normative or rolespecific behavior (Spindler and Stary 2017).

Motschnig-Pitrik and Nykl (2001) argued "that problem solving within an individual's context is particularly effective, since it most closely matches the living, sensing, and experience of this individual and has the highest potential for disposition and reuse of the individual's experience" (p. 275). Agogic at the workplace-here referred as work-agogy-(see Fig. 2.7) indicates sensing crucial to cognitive intentional acts, to be captured by in-depth asking:

- WHAT IS? What did you see, hear, smell, taste, feel? What happened, when and how? Can you describe it in detail?

- WHAT SHOULD BE? Which perspective, which sense do you see? What needs to be achieved? Which priorities do you want to set? What do you want exactly? And why? Which state satisfies you?

- WHY? Which meaning do the observations have for you? Which relations do you recognize? What do you reckon? How can you explain that? What are your conclusions? 


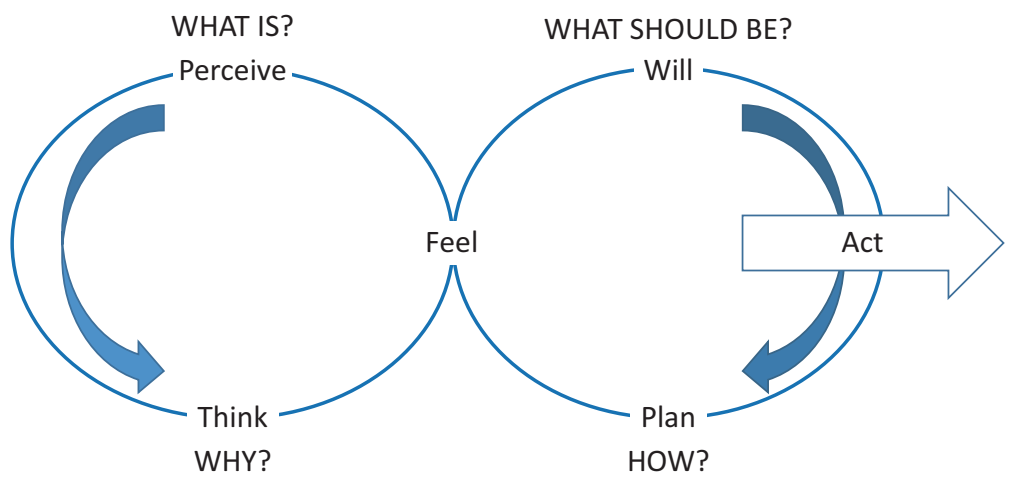

Fig. 2.7 Work-agogy (according to Arbeitsagogik.ch)

- HOW? How to proceed? Which means shall be used? Which tactics shall we chose? What is to be done? Who does what, with what, whom, when, and how?

As indicated in Fig. 2.7, work-agogy in the context of work processes captures the rationale of doing in terms of perceiving a situation and cognitive reflection of perceived information, as some pre-processor to doing, guided by intention and planned action. According to that model, various subsystems are involved in preparing actions through reflecting outer-space information and bringing action from inner space processing to become visible for others in the outer space.

According to Rogers (1961), a facilitating social atmosphere is required for understanding and acceptance of the individual to develop ('grow'). It will then "will become more similar to the person he would like to be; will be more self-directing and self-confident; will become more of a person, more unique and more self-expressive; will be more understanding, more acceptant of others; will be able to cope with the problems of life more adequately and more comfortably" (Rogers 1961, pp. 37-38). In this, the inner space of a person can become part of the outer inner space, for example, through his/her understanding the role, as required for co-creating the organization of work.

Figure 2.8 visualizes the results of developing a reflective practice for situations-to-be. We refer to the actors (represented by individual Selfs in various roles [capturing their inner space] and involved in specific situations), 


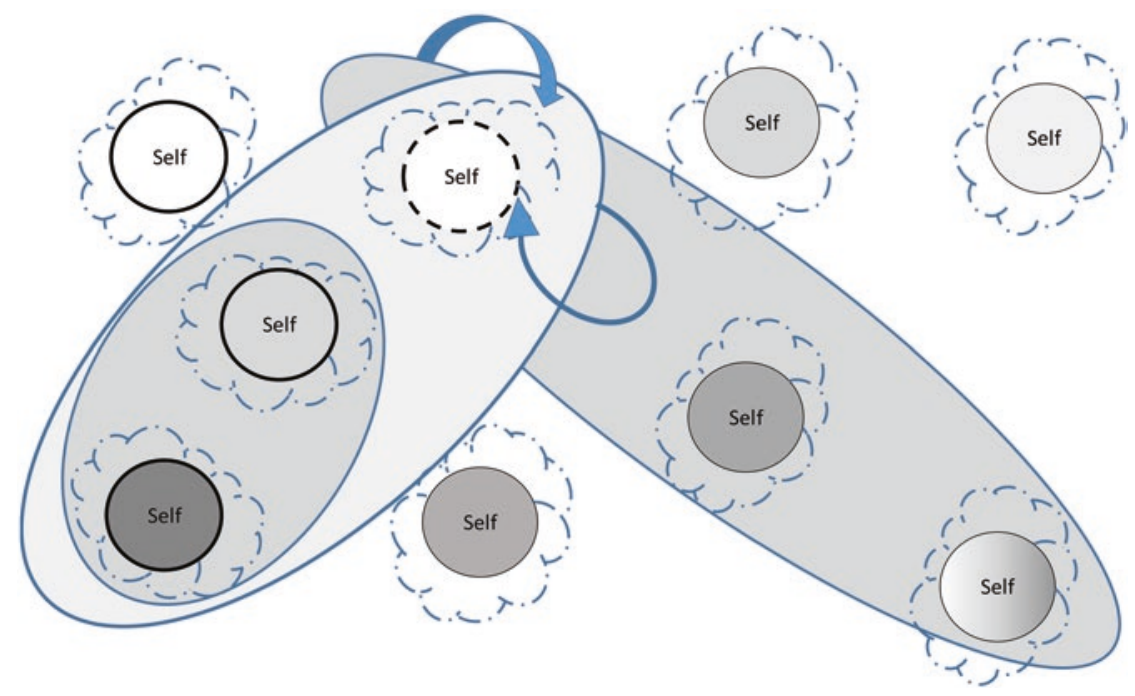

Fig. 2.8 Creating a reflective practice for situations-to-be

being part of a complex systems in terms of a System-of-Systems. Both, the situation and the System-of-Systems represent the outer space of an actor. As indicated by the upper arrow on top of the Systems-of-Systems in the figure, actors need to develop an understanding of novel system constellations. Potential scenarios need to be evaluated, like in the shown case adding actors with gray background as part of an additional System-of-Systems (depicted from the middle to the lower right) consisting of three systems, where the considered Self (white background) is in the role of potentially becoming part of two Systems of Systems, leading to an enriched overall system.

\subsection{Focusing While Utilizing Multiple Perspectives}

Individual introspection into personal views on one's work by means of externalization can be considered a prerequisite for the development of common views on work and organizational improvement, respectively. The role of the individual in this context has not only been an issue in 
organizational research (e.g., Sachs 1995; Suchman 1995), but has also been addressed regarding the learning aspects for both individuals and groups. Theories originating in cognitive sciences offer an explanatory approach for how individual perceptions and pictures and (organizational) reality are mutually influenced. One of these is 'mental models' (cf. Johnson-Laird 1981; Ford et al. 1991), as they are considered to explain the foundation of thought processes. Whenever humans are confronted with situations in which they should act, they create an explanatory model in their mind. The contents of this model are based on individual perception of the situation, previous experiences, and personal values.

In organizational settings, mental models also guide an individual's way of interacting with others. This includes decisions on when to explicitly cooperate, with whom to cooperate, in which way, when to expect input from others, and when to deliver results to others. In order to interact successfully, the individual mental models have to fit each other. Mental models are purely cognitive constructs and are per definition inaccessible to others. In order to align mental models, the involved individuals first have to make their mental models visible to others. In many situations, verbal expressions may not lead to sufficient visibility required for successful alignment. When the work setting is perceived as complex or when unexpected contingencies arise, more explicit representations of mental models are needed (Russell et al. 1993; Klein et al. 2006).

Explicit representations of mental models are called 'externalizations'. In collaborative work, externalization is necessary to provide people with a common ground for sharing and negotiation of different views. Shared views in turn change individual mental models. In this way, a common understanding of interaction emerges. Externalization can be supported methodologically and by using tools (Pirnay-Dummer 2006, see also, Ifenthaler (2006) for an overview of established techniques in this field).

Structure elaboration techniques are an effective means to create physical representations of mental models (Dann 1992). In a moderated process (the dialogue-hermeneutic method), the participants create a graphical representation of their mental models by placing labeled cards on a modeling surface. Subsequently, they relate each other using associations. Dann (1992) has stressed the importance of the immediacy of rep- 
resentation in the structuring process. This immediacy is attained by the physical creation of the model. Participants immediately refer to a physical representation rather than abstract items. They create and modify the model in a dialogue-based way until reaching consensus about what is represented. Mental models of individuals are externalized, questioned, and can be modified at the same time. The procedure ends once all participants feel comfortable with the result.

Structure elaboration techniques are highly sophisticated approaches with respect to the specification of both, the methodology and the instruments to be used. However, their suitability for the externalization of mental models has already been evaluated empirically (Groeben and Scheele 2000; Ifenthaler 2006). Some researchers (e.g., Dann 1992) have suggested that structure elaboration techniques should always be adapted to the case at hand, for example, in terms of prescribed modeling elements or methodology. Presumably, such an adaptation could be necessary when used for externalization.

Due to its minimalist approach to semantics and syntax, concept mapping (Novak and Canas 2006) is widely used to elaborate on structures. These maps contain mutually linked nodes corresponding to (mental) concepts. In contrast to other structure elaboration technologies, concept mapping does not explicitly aim at creating consensus of how to interpret the externalization among the involved individuals. In concept mapping, concepts are collected directly during structuring, which allows for immediate, contextualized specification of new aspects of the model. Concept maps also support defining concept classes (such as 'persons', 'tasks' etc.) for additional (hierarchical) structuring and do not give any constraints on which or how many classes to use.

As such, the concept mapping approach is considered to be suitable for externalization of mental models (Pirnay-Dummer 2006). In the course of mapping, constructs are arranged according to an issue of interest, for example, individual organization of work (Oppl 2006). The constructs are named and structured by associating them. In this way, a contextual specification is established. Such mappings have already been applied in structured domains, such as mathematics, allowing for individually arranging domain content (Brinkmann 2003), or for generating meaningful representations from scratch according to individual mental mod- 
els (Coffey and Hoffman 2003). While for the first setting, the focus of mapping lies on the arrangement of previously known elements, the latter requires an open space to identify, name, and arrange content.

Some of the existing tools for structure elaboration, do not only provide support for the articulation process itself, but also allow assessing the quality of representations, for example, based on metrics derived from graph-theory for concept maps (Ruiz-Primo and Shavelson 1996). Other tool approaches offer a tight integration with the computer desktop environment and enable links to digital resources (see for concept maps, Canas et al. 2004). In particular, concept maps seem to have potential for usage in daily work, as they can be integrated into and consulted from existing (computer-supported) workflows.

At the center of articulation in the course of knowledge elicitation is the ability to learn about mental models. Structure elaboration in terms of mapping mental constructs to diagrammatic expressions has already turned out to be useful to generate ideas, to design a structure, such as organization of work, to communicate ideas, and to aid learning by explicitly integrating new and old knowledge. By communicating diagrammatic representations, such as concept maps, misunderstandings can be avoided (Ausubel 2000), a prerequisite for shared reflection and collective knowledge creation.

Although the format of representing articulated knowledge may be open with respect to syntax and semantics, as in the case of structure elaboration, elicitation of work knowledge can profit from a fundamental perspective on human work. It can be directed towards information or communication, as different strategies of organizing knowledge are related to them (F. Fuchs-Kittowski and Fuchs-Kittowski 2007): formalization, codification, personalization, and socialization. In particular, the latter is of importance for alignment and shared understanding-see Table 2.1 (according to F. Fuchs-Kittowski and Fuchs-Kittowski 2007).

Finally, eliciting knowledge is influenced by the individual perception and representation of work practices (Bossen 2017). For instance, the description of a scheduling procedure for consultation of medical experts in an outpatient clinic is likely to differ whether one asks the patient, administrative staff, or the medical experts. Hence, the challenge of elicitation in this context is grounded in the role- or task-specific perspective 


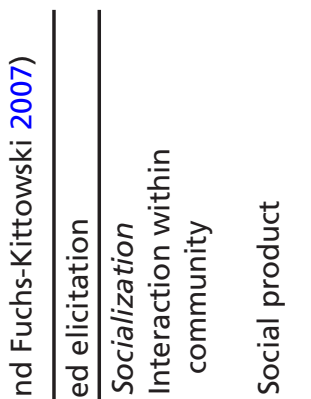

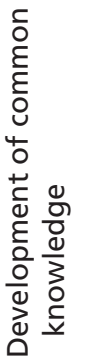

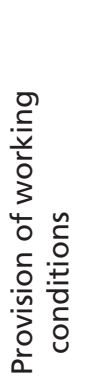

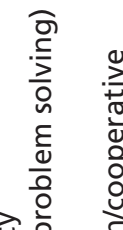<smiles>CCCCCCCC</smiles>

\%ั

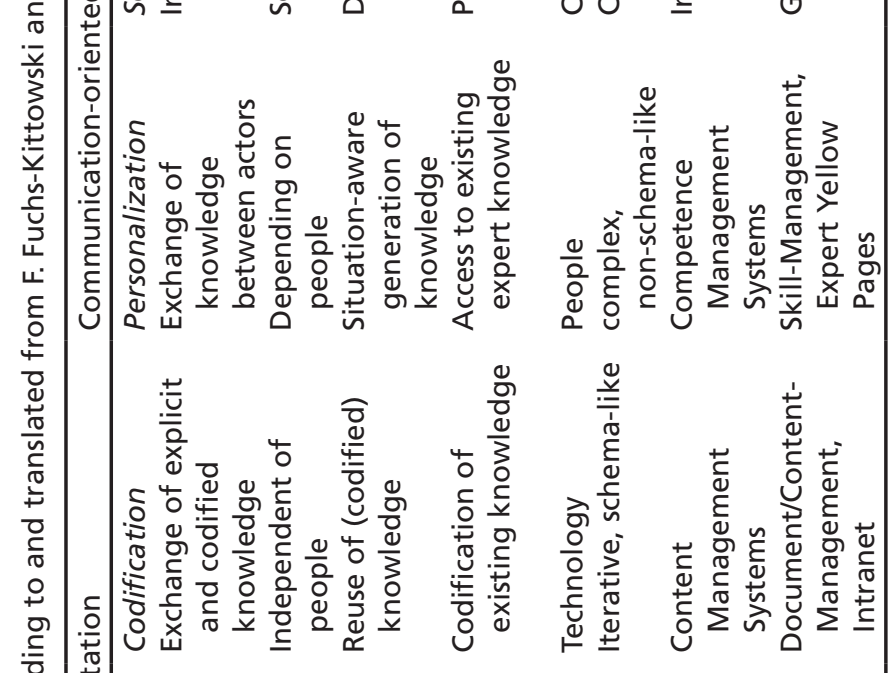

莺

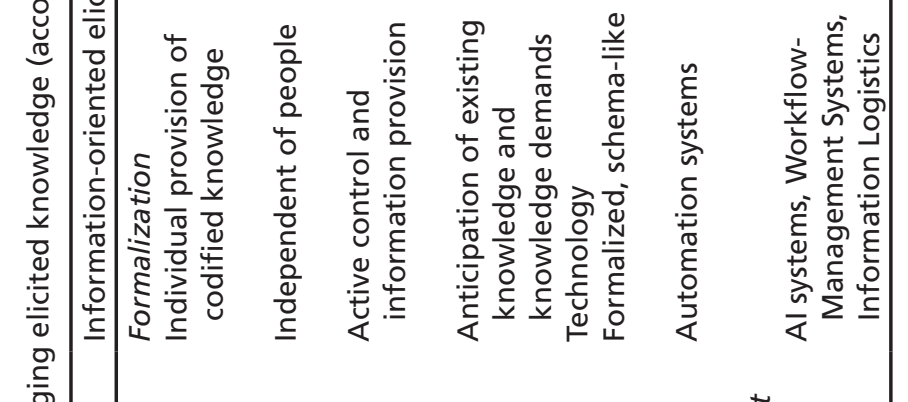

:

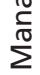

ì 
the stakeholder tasks. It lays ground to sociological theories, such as Strauss' theory of action.

He opposed representations of action as if concerning an act (singular) with a beginning and an end by one actor following a set course of action. This linear and 'rationalistic' - in the sense of producing a simplifying and rationalizing depiction - can be contrasted to an interactional model: Looking closer, acts come forward as involving multiple steps in which emergent circumstances and the interaction with other actors have to be monitored by the actor, who has to adjust her actions to the contingencies arising in an ongoing manner, and which results in 'an act' as requiring efforts of aligning, coordinating, monitoring and being more convoluted than in former the linear representation. (Bossen 2017, p. 79; Strauss 1993)

Bossen (2017, p. 79f) concludes that "representations of practices should then not be made too rashly and should build on detailed empirical knowledge: Streamlining work into linear, rational models entails the risk of ignoring or forgetting central features of the apparent mess of work. Further, since no description of a phenomenon can capture all its aspects, but will highlight some and push others to the background, the act of representing requires making choices of what to make visible" (Suchman 1995).

Figure 2.9 visualizes the situation where different stakeholders pursue different interests in various situations, and may take different perspectives upon work practices in their mental models, including the interaction with actors in specific roles. In the figure, Self denotes an actor who plays a certain role in a certain situation on which he/she has a certain perspective according to individual perception of the corresponding work. As shown in the figure, each actor has a certain perspective which might overlap with others or not (represented by stars in the figure). The perception can depend on the role and situation of an actor, as shown by the Self with the white background in the figure. The lower right part of the figure shows a constellation of overlap as perspectives can be shared and include the interaction beyond plain information exchange.

Once articulation of work knowledge makes visible the multiple perspectives on work due to the individual mental models of tasks or roles, the design and structuring of work can be enriched by parameters determining the quality, and final success of operating a business. 

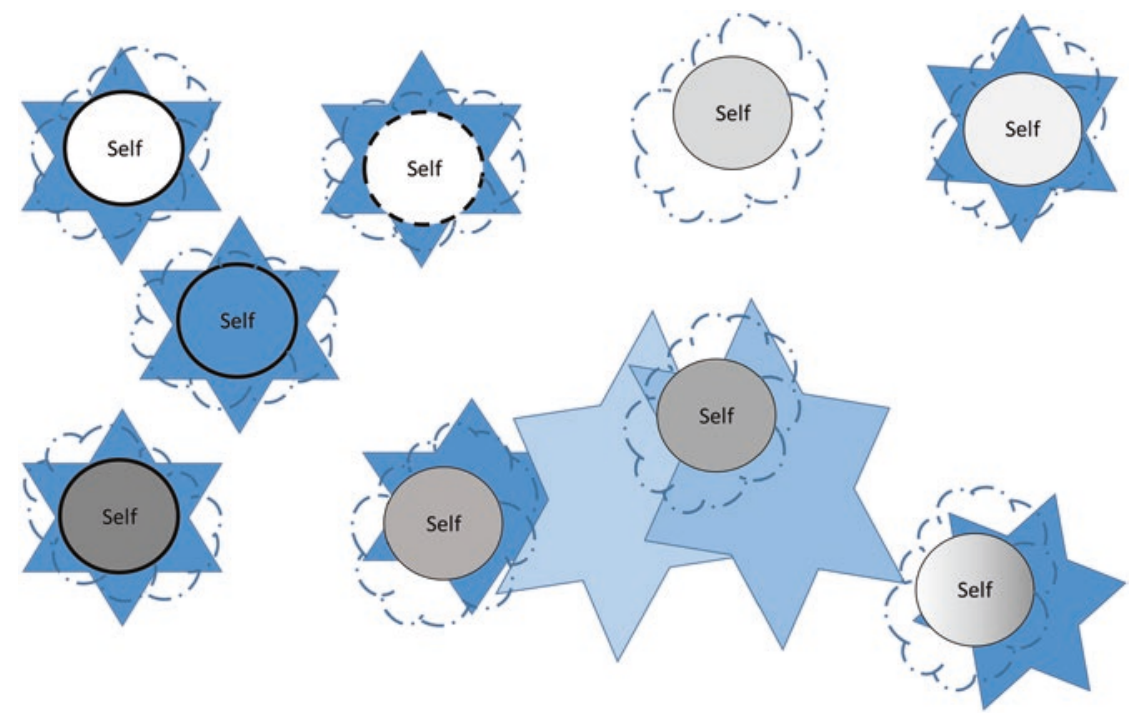

Fig. 2.9 Focusing while utilizing multiple perspectives

\subsection{Articulating Intangible Assets}

"How people work is one of the best kept secrets in America." The (location-independent) validity of this statement by Wellman (cited in Suchman 1995) has been underlined in various contexts, for example, by Polanyi (1958) when referring to 'ineffable knowledge' that does not allow workers to reflect about their work without becoming conscious about work structures. Nonaka and Takeuchi (1995) even referred to the problems caused by changing those structures.

Strauss has pointed out the importance of Articulation Work (Strauss 1985 ) in that context. This term is dichotomous and has always to be considered in both of its meanings: Articulation Work is talking about one's work in order to be able to work together with others. Articulation Work is an integral part of work in general, particularly in the sense that it takes effort to realize it. Articulation Work is considered as a conceptual complement to 'Production Work', that is, the work dedicated to achieve organizational goals (Fujimura 1987). 
Most of the time, Articulation Work happens implicitly (Strauss 1988), that is, none of the involved participants consciously and actively communicates his/her view on his/her work. However, a common understanding is created by simply working together. This phenomenon corresponds to the phenomenon of socialization described in Nonaka and Takeuchi's Socialization, Externalization, Combination, Internalization (SECI)-model (Nonaka and Takeuchi 1995).

Similar findings have resulted from studies in work and cognitive psychology. It has been shown that an essential part of the user's task-relevant knowledge is tacit (i.e., unconscious). Knowledge either becomes tacit through automation of work procedures, that is, formerly explicit knowledge lapses into the unconscious and, by that, becomes tacit (Hacker 1998), or the tacit knowledge is acquired through implicit learning, that is, task-relevant knowledge is learned without awareness through personal experience and practical examples, similar to a master-apprentice relationship (Neuweg 2004).

In a variety of professions that rely on complex problem-solving capabilities and creativity like law, medicine, sales, teaching, or management, tacit knowledge is considered as a crucial factor for success (Sternberg et al. 1999). In particular, it plays a central role in dealing with critical, that is, non-routine situations at work (Büssing et al. 2002). The main characteristic of the tacit dimension of knowledge is that it is difficult to communicate and formalize (Nonaka and Takeuchi 1995; Polanyi 1966). Consequently, tacit knowledge is difficult to capture with traditional task elicitation methods like questionnaires, surveys, structured interviews, or analyses of existing documentations. The task analyst simply does not know what kind of questions to ask (Beyer and Holtzblatt 1997). When eliciting user-task information, developers, therefore, have to deal with the tacit dimension that indwells work procedures.

As in established and routine task settings, workers are not always conscious of how and why they act in a certain way, problems that might occur once established work practices need to be adapted (Gasser 1986; Gerson and Star 1986). However, the term 'established work practices' is ambiguous. Strauss (1988) and Fujimura (1987) distinguish routine work form problematic work, the latter increasing the need for Articulation Work. Regarding routine work, Strauss however states that one man's routine of work is made up of the emergencies of other people 
(Hughes 1971 cited in Strauss 1993, p. 43). According to this understanding, established work practices are only those procedures where all involved people are able to routinely handle the steps required to complete the work.

Consequently, established work practices can turn into problematic situations anytime. Introducing new people or changes in the working environment can lead to unforeseeable contingencies that require Articulation Work to be resolved. Changes in the working environment that cause the established work practice to break down can be as simple as printers running out of paper (Bendifallah and Scacchi 1987). This is a contingency that can be resolved rather quickly and simply. There are, however, situations that require more effort to be resolved (ibid.).

According to Strauss, explicit Articulation Work (in contrast to implicit one) (Strauss 1988) becomes increasingly important, the more complex and problematic a work situation is perceived by the people involved ("Problematic interactions involve 'thought', or when more than one interactant is involved then also 'discussion'. An important aspect of problematic action can also be 'debate'-disagreement over issues or resolutions" (Strauss 1993, p. 43)).

Since there is still a strong tendency towards standardization and explicit definition of work routines (cf. business process modeling Scheer 2003), workers are considered more and more (error-prone) system elements from a socio-technical system. As such, their individual influence has to be reduced as far as possible. While this view has facilitated the development of mankind during the last centuries, it has clearly reached its limits, according to studies on work transformation (Sachs 1995).

Today's complex business environments require skills, which have not been considered important anymore for frontline workers. In settings, where exception handling might become the standard process, automated execution of workflows using human manpower does not work anymore. Much of what in former times has been regarded routine work (or operations) is fully automated today. Humans get in charge mostly when something goes wrong or cannot be decided based on a set of predefined rules. When people in such cases do not consciously know what is going on in their work environment-when their work is a secret to themthey experience troubles. In today's business settings consciousness of work practices is required increasingly, as 
- the demand for and to develop further skills needs to be identified (Hampson and Junor 2005)

- work practices and interfaces have to be negotiated in collaborative work settings (Strauss 1988)

- work processes needs to be improved continuously (Caetano et al. 2005)

- exceptions need to be tackled in a straightforward way (Gerson and Star 1986), and

- work practices need to be communicated to others for support (Herrmann et al. 2004)

The common prerequisite of all these settings is individual awareness about how work is done, in which context it happens, which goals are to be reached by which skills. Sachs (1995) suggests taking an alternative view on work, regarding not only organizational tasks, but also the given human-activity-centered aspects, the context of work and its understanding by human beings, as they are highly relevant for economic success.

According to Strauss (1988), explicit Articulation Work aims at unveiling these issues and making them communicable to others. It enables people to externalize their individual views on work, to reflect upon it, and to present. A means to support explicit Articulation Work is using representations of work as a basis and facilitator for externalization (Suchman 1995) ("A map or other representational device is a piece of craftwork, crafted in the interest of making something visible. Things are made visible so that they can be seen, talked about, and potentially manipulated," ibid.). Representations of work in terms of Suchman (ibid.) "(...) are interpretations in the service of particular interests and purposes, created by actors specifically positioned with respect to the work represented."

In this respect, it doesn't matter, "(...) whether (these representations are) created from within the work practices represented or in the context of externally-based design initiatives (...)" (ibid.). Following Suchman, representations of work can either be a result of work or describe work from a bird's eye view (with people stepping out of the system to describe it)—or both. In terms of explicit Articulation Work, representations from a bird's eye view are the results of articulation. Actual results of work might serve as a basis for explicit articulation and facilitate it, but they are not in the focus of this work. 
Representations from a bird's eye view can be codified in different forms. A common form is to use textual descriptions of work (Kyng 1995). Textual codification allows capturing work with the whole expressional power of natural language. Reflection about and communication of the structure of work, however, is better facilitated by diagrammatical representations or graphical models (Hahn and Kim 1999). Models have proven to serve as mediators and boundary objects for people communicating about their work (Boland and Tenkasi 1995, cited in Krogstie et al. 2006).

Models are built using modeling languages using a syntactically fixed and semantically predefined set of symbols. These constraints are necessary for further processing, but appear to hinder the modeling process itself (Jørgensen 2004). Most modeling languages force modelers to use representational schemes that do not necessarily correspond to their individual understanding of work (Oppl 2018). This mismatch often leads to situations where the modeling language is inappropriate to express what people consider relevant_- "Indeed, I would go so far as to claim that constraining practitioners during early design to use some fixed notation with a fixed semantics would slow them down, by forcing them to pay more attention to the limitations of the notation than to the details of their problem" (Goguen 1993).

For support of explicit Articulation Work, it has to be assured that all aspects of work considered relevant by people can be expressed by the modeling language (Oppl 2016). Moreover, modeling requires the recognition of relevant real-world phenomena, to abstract and conceptualize them, and to represent them with the means of the modeling language. These are non-trivial tasks, which might be very challenging-if not overstraining - for people inexperienced in modeling (Goguen 1993). Articulation Work, however, has to be performed by everybody involved in the work process (Strauss 1988), also-and especially-frontline workers, who very rarely have experience in modeling (Oppl 2017).

Figure 2.10 visualizes the recognition of intangible assets, both, on the level of individual actors, and the collective layer. As a prerequisite for designing situations-to-be, actors need to reveal and communicate information that influence their perception, thinking, and doing - they need to engage in explicit Articulation Work. In the figure, the actors are rep- 

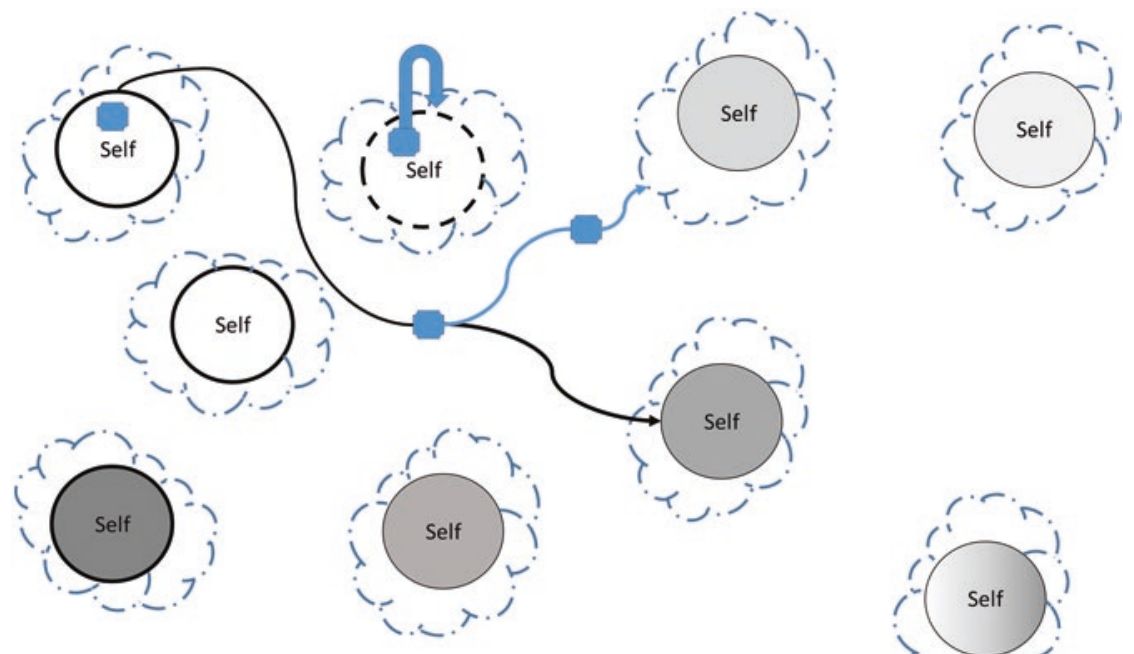

Fig. 2.10 Articulating intangible assets

resented by their individual Selfs taking various roles and being involved in various specific situations. They might have blind spots, indicated by the big dots in the figure worth being elicited and evaluated in terms of implications for themselves, and when interacting with others (as indicated by the links between Selfs).

\subsection{Engage in Alignment for Collective Intelligence}

Herrmann et al. (2002) have shown that workers should not only be able to describe their particular view on the assigned work tasks, but also coconstruct a common understanding of collaborative work tasks. Such type of participation facilitates technology development, even when different paths to accomplish a certain task are followed by individual workers. Empirical results from work psychology, too, give evidence that there are many alternative efficient and effective procedures when users have freedom in their task accomplishment procedure (Ulich 1994). 
Hence, when dealing with different users and different individual perception of tasks and task accomplishment procedures, elicitation techniques should support the elicitation of both, idiographic (i.e., the individual user's perception of the task) and co-constructive (i.e., common aspects of user groups in task perception) user-task information. In order to achieve this objective, the elicitation, as well as the representation of user-tasks has to be context-sensitive (Mirel 2004). However, from the method perspective successful elicitation should avoid the influence of representational structures to cognition, in particular, when capturing the tacit dimension, value both, individual differences and commonalties of user-work information (Hemmecke and Stary 2006).

Although articulation can be guided by modeling, thus leading to representations of work knowledge, developing a shared understanding of such manifestations should be considered a learning process (Seel 2003). Those processes are most successful when the gap between mental models and representations can be kept minimal. In her extensive empirical work, Maria Montessori has identified several cornerstones for successful knowledge creation and acquisition to that respect (cf. Montessori 2005; Ludwig et al. 2002):

- Both have to be tuned to individual types of stakeholders. Learning should be an individualized process that might also occur in group settings.

- Acquiring and creating knowledge are oriented towards individual acting. Stakeholders should acquire competence and skills directly working with subjects or manipulating content.

- Knowledge creation should be under the control of the stakeholders, including setting the stage for sensible learning phases (which are essential for understanding).

- The acquisition and creation of knowledge should lead to and be built on visible structures (inner structure requires external structure) with a maximum degree of freedom to act individually and express mental models accurately.

- Knowledge creation should be based on some material or pre-structured content to direct the attention of individuals. 
- Creating and acquiring knowledge should occur in a comprehensive, but focused way (in-depth concentration on the subject of acquisition). Subject-specific elements should be complemented by transformation tasks. For instance, business process modeling using event-driven process chains in ARIS (Architektur integrierter Informationssysteme; Architecture of Integrated Information Systems) (Scheer 2003) should be complemented by UML (Unified Modeling Language)-models, since the latter provide an additional, object-oriented perspective on process-model elements.

- Active acquisition should be observed by coaches, providing intervention on demand. Such a setting allows for misconceptions, faulty or misleading procedures, for example, caused by opinion leaders in group settings.

Maria Montessori's observation let her conclude that any learning process should be facilitated by allowing stakeholders to manipulate objects in a self-managed way. This process should be implemented in a wellprepared environment. This environment is shared with the mentor and/ or peers, for sharing experience, guidance, and help. However, the acquisition of knowledge is the responsibility of each stakeholder. The role of the stakeholder is to handle the material according to inherent properties of the content and few inputs provided by a facilitator. In the ideal case, the prepared environment guides the stakeholder to domain-specific properties and tasks that can be accomplished in a self-managed way using the manipulative elements of the environment—a strategy technological instruments aim to follow (Zuckerman et al. 2005).

The tasks that are traditionally performed in Montessori-oriented settings start on a straightforward level and become increasingly complex:

1. Structuring (Ordering) elements: Montessori considers (mathematical) structuring the training in exact thinking. She has recognized the domainspecific grouping of elements, the correct assignment of phenomena, and the multi-dimensional capturing of things in the world substantial for further acquisition processes. Exact working in natural sciences, however, requires the combination of motor- and sensor experience.

2. Communication of models or concepts and transformation processes by means of language. The verbal handling and the semantically cor- 
rect application of domain ontologies are at the center of knowledge acquisition and creation. Language has to be materialized and embodied in cognition.

3. Cosmic education through comprehensive and symbolic application of knowledge. Montessori's constructionist approach envisions learning to occur in and lead to a well-organized 'home' with harmonized arrangements and objects that can be found according to their scope of use.

For Maria Montessori, the exploration of the environment and selfmanaged handling of content elements is the key to comprehensive and holistic understanding. Stakeholders should (re)construct knowledge in an environment prepared accordingly. The environment has to contain the means for self-education. It has to contain activating objects of interest for sharing, acquiring, or creating knowledge, rather than isolated pieces of information or objects without indication of their usage.

Facilitators should motivate the acquisition, facilitate the acquisition and transfer process, and resolve conflicts. They serve as mediators between content elements and individuals in the environment. Understanding focusses on content elements and their interactive handling.

In case digital work should enrich human perceptual capabilities, metaphors could help when constructing socio-technical work spaces (cf. Turkle 1998, p. 291; Oppl and Stary 2011b). Thereby, humans do not interact as a separate part of the socio-technical environment, they are part of it. This phenomenon is also termed immersion. Immersion facilitates active participation in processes (rather than consumption of visual information) through manipulation of objects (Oppl 2006).

Given immersion, another factor moves also to the center of interest: the capability to share experiences and to interact in a common context even over large distances. It is the idea of structural and dynamic networking. Focusing on networking and context-sensitive interaction allows for more than the reproduction of predefined sequences of interaction with a limited set of features. It allows for exploration, selfmanagement, and social process support. In this way, they support human-centered concept developments, for instance to move forward 
from 'simple' training mechanisms in the sense of reproducing activities and facts in a predefined domain towards collaborative knowledge exploration in an open space.

With respect to content, Norman and Spohrer (1996) have found out that high quality material in general should provide a high degree of confidence in their (i) usefulness, (ii) interest (which is particularly in line with Maria Montessori-see above), and (iii) effectiveness. They have elaborated their principles of 'learner-centered education' in terms of individual engagement, effectiveness, and viability. Engagement means collaboration with highly motivated learners in the course of education. It is enabled through "rapid, compelling interaction, and feedback" (ibid., p. 26). Effectiveness, in the sense of Norman and Spohrer, denotes the depth of understanding and the skills students acquire. The viability addresses the seriousness of the problems tackled, the relevance of the topics, and the accuracy of tools for the process of knowledge creation and representation.

One way to meet these objectives in virtual settings or augmented environments has been to recognize the multiple dimensions of knowledge sharing and creation and to tackle them explicitly. For instance, Resnick et al. (1996) have observed: "Educational technology has too heavily emphasized the equivalent of stereos and CDs and not emphasized computational pianos enough" (ibid., p. 42). The researchers' goal was to develop computational construction kit development "enabling people to express themselves in increasingly ever-more complex ways, deepening their relationships with new domains of knowledge" (ibid., p. 42).

The theory of constructional design focuses on a constructionist approach to individual knowledge acquisition. Constructional design of content is a type of meta-design (designing for designers) to support learners in their own design activities and thus leading to hands-on experience in construction. Papert (1993) argues for a constructionist approach to learning: In design-based learning, things that people design (such as Lego ${ }^{\circ}$ constructions) "serve as external shadows of the designer's internal mental models. These external creations provide an opportunity for people to reflect on - and then revise and extend-their internal models of the world" (Resnick et al. 1996, p. 42). 
Engagement, as demanded by Norman and Spohrer, needs to be implemented through something more than learning-by-doing, since, in contrast to learning-by-doing little attention has been given to the "general principles governing the kinds of 'doing' most conductive to learning” (Resnick et al. 1996, p. 42). Two general principles should guide the design of activities binding individuals to an object: personal and epistemological connection. They have been defined as follows:

- Personal connections. Constructions kits and activities should connect to users' interests, passions, and experiences. The point is not simply to make the activities more 'motivating'. When activities involve objects and actions that are familiar, users can draw on their previous knowledge, connecting new ideas to their pre-existing intuitions.

- Epistemological connections. Construction kits and activities should connect to important domains of knowledge-and, more significantly, encourage new way of thinking (end even new ways of thinking about thinking). A well-designed construction kit makes certain ideas and ways of thinking particularly salient, so that users are likely to connect with those ideas in a natural way in the process of designing and creating. (Resnick et al. 1996, p. 42)

Materials enabling rich learning experience should provide both types of connections. Two ways of implementations have been pursued: enrichment of existing objects and virtualizing the core material. In the 'Things That Think' initiative (MIT's Media Lab), everyday objects should embed computational capabilities, not only to accomplish particular tasks more cheaply or easily or intelligently, but to enable people to think about things in new ways (Weiser 1991). One solution was programmable bricks. Structures and mechanisms have been developed using programmable Lego ${ }^{\oplus}$-bricks for car and castles building including behaviors. Typical creations are: real animals, step-trackers, science experiments, and smart rooms. The program is stored in the brick after a download from the PC. Actually, a brick is a very personal computer. In this way, a strong personal connection is established, since the brick is part of the learners' culture and life. The bricks allow to compare artificial with natural beings (e.g., robots and animals) as well as to understand complex 
systems' behavior, for example, feedback strategies. In that way, an epistemological connection can be set up.

Narrative-based, Immersive, Constructionist/Collaborative Environments (NICE's) underlying theoretical framework "combines constructivist educational theory with ideas that emphasize the importance of collaborative learning and narrative development" (Roussos et al. 1997, p. 62). Constructivist pedagogy is one "by which learners actively construct and interrelate knowledge and ideas" (ibid.). These findings lead us to the conclusion that the more objects are available in a concrete form and way, and the more focused communication occurs, the more effectively (and efficiently) knowledge-creation and sharing can be supported (Oppl and Stary 2011a, 2014).

The involvement of individuals seems to play a central role for knowledge acquisition and throughout the process of creating mutual understanding, redefining the role of developers: "The process of constructional design is not a simple matter of 'programming in' the right type of connections" (Resnick et al. 1996, p. 49), since behavior is not predictable by developers. "Developers of design-oriented learning environments need to adopt a relaxed sense of 'control' " (ibid.) in the sense of creating 'spaces' for possible activities and experiences rather than limiting the interaction space (which, again, is in line with Montessori). However, developers have to make those spaces dense with personal and epistemological connections. Then, there will be defined regions, both appealing and intellectually interesting (as demanded by Montessori or Norman and Spohrer).

Understanding immersion in the sketched sense of individual and social engagement in knowledge creation and sharing processes enables more than scanning and retrieving information. Both, constructionist and constructivist acquisition support the personal and epistemological connection of individuals to subjects.

From the perspective of socio-technical design of digitized work systems with such engaging environments for articulation and representation, the emotional side has to receive attention, equal to social and cognitive aspects of knowledge creation and sharing. Hedonic qualities address the matter of emotion and pleasure when persons interact with artifacts. For interactive systems, they have become a matter of competitiveness (Subramanya and Yi 2007). The factors contributing to a rich 
and satisfying user experience include interactions "that are natural, intuitive, simple, pleasant, easy to remember, and adaptive to individuals' idiosyncrasies" (ibid., p. 114). Millard et al. (1999) have shown joy of using an artifact might increase the quality of work significantly. Several dimensions have been identified for design taking into account user experience:

- Devices: Factors related to this dimension comprise the use of colors for display, and touch-sensitive screens.

- Communication and social interaction: Relevant issues to that respect are the provision of a (virtual) vicinity, feelings of personal touch, gestures, and differentiated communication based on relationship to persons.

- Application: Pleasing user interaction is based on a minimal feature list, non-intrusive media (e.g., hands-free usage of mobile devices), personalization of content, and the combination of stimuli or multi-modality.

Although there is a long tradition in handling user properties and individual differences in human-computer interaction (Egan 1988), only few engineering practices tackle them in connection to design. The current practice taking into account multiple perspectives focuses on modeldriven development (Gruhn et al. 2007; Petrasch and Meimberg 2006). It enforces an implementation-independent representation of interactive systems, relying on diagrammatic representations to reflect a status-quo and exchange design ideas. The models allow a structured procedure, due to the mutually tuned representation of content-a demand that has also been uttered in the context of structured knowledge creation and sharing, with respect to learning resources (Kurzel et al. 2003).

Figure 2.11 visualizes Selfs actively involved in sharing and re-arranging information they have been revealing through the activities described in the previous subsections, such as externalizing intangible assets. Following the reflective practice for situations-to-be, actors in their various roles and involved in specific situations need to align their interactional understanding, in order to proceed with developing their organization of work. As indicated by the three clouds, aligned situations emerge in the course of alignment, based on a common understanding of articulated knowledge. 


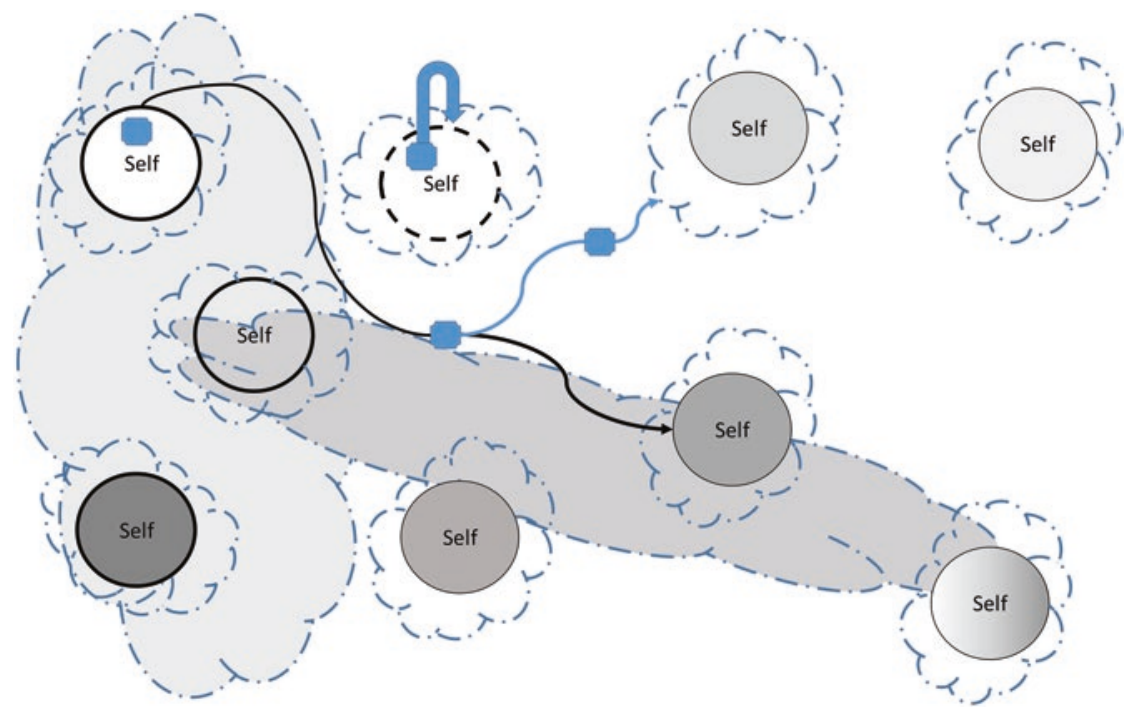

Fig. 2.11 Engage in alignment for collective intelligence

\subsection{Synthesis}

In Table 2.2, we give an overview of the requirements collected from the various disciplines and approaches. They have been detailed in the previous sections. We synthesize their meaning for each of the requirements. It becomes evident that the starting point is the individual Self of each actor which is challenged to open up for developing awareness, if not indepth understanding, of

- roles taken by the actor

- context given by situations the actor perceives to be relevant

- complex systems the actor is part of

- reflecting on past, present, and future scenarios of work the actor participates in

- how to focus while taking different perspective on work processes

- intangible work assets provided and required by the actor

- consolidating actor-specific work knowledge when aiming for collective intelligence 
Table 2.2 Summary of elicitation requirements

\begin{tabular}{|c|c|}
\hline $\begin{array}{l}\text { Elicitation } \\
\text { requirement }\end{array}$ & Description \\
\hline $\begin{array}{l}\text { Awareness on } \\
\text { role(s) and their } \\
\text { management }\end{array}$ & $\begin{array}{l}\text { Roles constitute the appearance of individual actors and } \\
\text { can be part of various contexts. Their set up is relevant } \\
\text { to how stakeholders get involved in work knowledge } \\
\text { elicitation. }\end{array}$ \\
\hline Situation Awareness & $\begin{array}{l}\text { Role- or task-specific activities need to be framed by } \\
\text { information of the situation an actor is part of. }\end{array}$ \\
\hline $\begin{array}{l}\text { Conceptual } \\
\text { understanding of } \\
\text { complex systems }\end{array}$ & $\begin{array}{l}\text { Networked and continuous development of socio- } \\
\text { technical settings increases complexity of systems which } \\
\text { requires concepts to handle it for reflection and } \\
\text { change. }\end{array}$ \\
\hline $\begin{array}{l}\text { Creating a reflective } \\
\text { practice for } \\
\text { situations-to-be }\end{array}$ & $\begin{array}{l}\text { Theories influence mental model building, either } \\
\text { consciously or unconsciously. Both need to be tackled } \\
\text { for articulating the future. }\end{array}$ \\
\hline $\begin{array}{l}\text { Focusing while } \\
\text { utilizing multiple } \\
\text { perspectives }\end{array}$ & $\begin{array}{l}\text { Determining the target of eliciting work knowledge } \\
\text { becomes more focused when looking through different } \\
\text { glasses on work. }\end{array}$ \\
\hline $\begin{array}{l}\text { Articulating } \\
\text { intangible assets }\end{array}$ & $\begin{array}{l}\text { Elicitation has to tackle both, explicit and implicit } \\
\text { knowledge on work, in order to achieve a complete } \\
\text { picture of the relevant work situation. }\end{array}$ \\
\hline $\begin{array}{l}\text { Engage in } \\
\text { alignment for } \\
\text { collective } \\
\text { intelligence }\end{array}$ & $\begin{array}{l}\text { Being part of a system plays a crucial role in externalizing } \\
\text { knowledge, as one is the observer who needs to } \\
\text { observe him/herself while being an integral part of a } \\
\text { work organization. Of particular importance is } \\
\text { intelligibility and purposeful involvement when one's } \\
\text { implicit knowledge is codified to be understood by } \\
\text { other stakeholders. }\end{array}$ \\
\hline
\end{tabular}

The respective individual reflection processes lay the ground for the development of collective intelligence, which frames the articulation alignment activities, which eventually lead to embodiment into work processes and finally, business operation.

From a procedural perspective, elicitation requires

1. A preparation of the setting, actors, and instruments. It includes the scope or universe of discourse, such as a business case, a motivating articulation environment including graspable material, and actors willing to learn both, express their mental models, and engage in cocreative reflection and generation processes 
2. Situation-sensitive articulation features as different people externalize knowledge on roles and work tasks differently

3. Facilitation encouraging stakeholders to look beyond well-established boundaries and patterns, and deal with high complexity of work situations and organizational structures

4. Representational alignment as a consolidated representation serves as a baseline for documentation and further development

5. Organizational alignment once elicited knowledge should be embodied in the workspaces of an organization

We will use this table and procedural cornerstones to put the results of the next sections into the context of elicitation requirements. Methodological approaches to articulation and alignment of mental models as well as corresponding tool support can be considered with respect to these requirements. They allow appraising the results concerning their effectiveness and usefulness in dynamic work practices in digitalized work settings.

\section{References}

Ackerman, Mark, Michael Prilla, Christian Stary, Thomas Herrmann, and Sean Goggins. 2017. Designing Healthcare That Works: A Sociotechnical Approach. Academic Press.

Adler, Susan. 1991. The Reflective Practitioner and the Curriculum of Teacher Education. Journal of Education for Teaching 17 (2): 139-150 (Taylor $\&$ Francis).

Allee, Verna. 2009. Value-Creating Networks: Organizational Issues and Challenges. The Learning Organization 16 (6): 427-442 (Emerald Group Publishing Limited).

Ausubel, J. 2000. The Acquisition and Retention of Knowledge: A Cognitive View. Kluwer.

Barwise, Jon, and John Perry. 1981. Situations and Attitudes. The Journal of Philosophy 78 (11): 668-691 (JSTOR).

Bendifallah, S., and W. Scacchi. 1987. Understanding Software Maintenance Work. IEEE Transactions on Software Engineering 13 (3): 311-323.

Beyer, H., and K. Holtzblatt. 1997. Contextual Design: Defining CustomerCentered Systems. Morgan Kaufmann. 
Boland, Richard J., Jr., and Ramkrishnan V. Tenkasi. 1995. Perspective Making and Perspective Taking in Communities of Knowing. Organization Science 6 (4): 350-372 (Informs).

Bossen, Claus. 2017. Socio-Technical Betwixtness: Design Rationales for Health Care IT. In Designing Healthcare That Works, 77-94. Elsevier.

Bounfour, Ahmed. 2016. Digital Futures, Digital Transformation: From Lean Production to Acceluction. Cham: Springer International Publishing.

Böhm, Winfried. 1997. Entwürfe Zu Einer Pädagogik Der Person: Gesammelte Aufsätze. Julius Klinkhardt.

Brey, Philip. 2005. The Epistemology and Ontology of Human-Computer Interaction. Minds and Machines 15 (3-4): 383-398 (Springer).

Brinkmann, Astrid. 2003. Graphical Knowledge Display-Mind Mapping and Concept Mapping as Efficient Tools in Mathematics Education. Mathematics Education Review 16 (4): 35-48.

Bronfenbrenner, U. 1981. Die Ökologie Der Menschlichen Entwicklung. Klett-Cotta.

Brown, John Seely, Allan Collins, and Paul Duguid. 1989. Situated Cognition and the Culture of Learning. Educational Researcher 18 (1): 32-42 (Thousand Oaks, CA: Sage Publications).

Brusilovsky, P., and D.W. Cooper. 2002, January. Domain, Task, and User Models for an Adaptive Hypermedia Performance Support System. In Proceedings of the 7th International Conference on Intelligent User Interfaces, 23-30. ACM.

Büssing, A., B. Herbig, and T. Ewert. 2002. Implizites Wissen und erfahrungsgeleitetes arbeitshandeln: Entwicklung einer Methode zur Explikation in der Krankenpflege [Implicit Knowledge and Experience Guided Working: Development of a Method of Explication in Nursing]. Zeitschrift für Arbeitsund Organisationspsychologie 46 (1): 2-21.

Caetano, A., A.R. Silva, and Jose Tribolet. 2005. Using Roles and Business Objects to Model and Understand Business Processes. In Proceedings of the 2005 ACM Symposium on Applied Computing, 1308-1313. New York: ACM Press.

Campos, Jordi, Maite López-Sánchez, Juan Antonia Rodríguez-Aguilar, and Marc Esteva. 2009. Formalising Situatedness and Adaptation in Electronic Institutions. In Coordination, Organizations, Institutions and Norms in Agent Systems IV, 126-139. Springer.

Canas, A.J., G. Hill, R. Carff, N. Suri, J. Lott, T. Eskridge, G. Gómez, M. Arroyo, and R. Carvajal. 2004. CmapTools: A Knowledge Modeling and Sharing 
Environment. In Concept Maps: Theory, Methodology, Technology, Proceedings of the 1st International Conference on Concept Mapping. Pamplona, Spain: Universidad Pública De Navarra.

Castells, Manuel. 1997. Power of Identity: The Information Age: Economy, Society, and Culture. Blackwell Publishers, Inc.

Cerulo, Karen A. 1997. Identity Construction: New Issues, New Directions. Annual Review of Sociology 23 (1): 385-409 (Annual Reviews).

Chan, S. 2001, October. Complex Adaptive Systems. In ESD. 83 Research Seminar in Engineering Systems, vol. 31, 1-9.

Coffey, John W., and Robert R. Hoffman. 2003. Knowledge Modeling for the Preservation of Institutional Memory. Journal of Knowledge Management 7 (3): 38-52 (MCB UP Ltd).

Colander, David, and Roland Kupers. 2014. Complexity and the Art of Public Policy: Solving Society's Problems From the Bottom Up. Princeton University Press. Dann, H.D. 1992. Variation Von Lege-Strukturen Zur Wissensrepräsentation. In Struktur-Lege-Verfahren Als Dialog-Konsens-Methodik, Arbeiten Zur Sozialwissenschaftlichen Psychologie, vol. 25, ed. Brigitte Scheele, 2-41. Aschendorff.

Dewey, John. 1910. Educational Essays. Bath: Cedric Chivers.

- 1933. How We Think: A Restatement of the Reflective Thinking to the Educative Process. Heath.

Dobbyn, Chris, and Susan Stuart. 2003. The Self as an Embedded Agent. Minds and Machines 13 (2): 187-201 (Springer).

Eberle, Peter, Christian Schwarzinger, and Christian Stary. 2011. User Modelling and Cognitive User Support: Towards Structured Development. Universal Access in the Information Society 10 (3): 275-293 (Springer).

Egan, Dennis E. 1988. Individual Differences in Human-Computer Interaction. In Handbook of Human-Computer Interaction, 543-568. Elsevier.

Ellison, Nicole, Rebecca Heino, and Jennifer Gibbs. 2006. Managing Impressions Online: Self-Presentation Processes in the Online Dating Environment. Journal of Computer-Mediated Communication 11 (2): 415-441 (Oxford, UK: Oxford University Press).

Ferscha, Alois, Clemens Holzmann, and Stefan Oppl. 2004a. Context Awareness for Group Interaction Support. In Proceedings of the Second International Workshop on Mobility Management \& Wireless Access Protocols, 88-97. New York: ACM. https://doi.org/10.1145/1023783.1023801.

. 2004b. Team Awareness in Personalised Learning Environments. In Proceedings of MLEARN 2004, Bracciano, Italy, pp. 67-72. 
Fichter, Lynn S., E.J. Pyle, and S.J. Whitmeyer. 2010. Expanding Evolutionary Theory Beyond Darwinism with Elaborating, Self-Organizing, and Fractionating Complex Evolutionary Systems. Journal of Geoscience Education 58 (2): 58-64.

Firestone, J.M., and M.W. McElroy. 2003. Key Issues in the New Knowledge Management. Butterworth-Heinemann.

Flood, Robert L., and Ewart R. Carson. 2013. Dealing with Complexity: An Introduction to the Theory and Application of Systems Science. Springer Science \& Business Media.

Ford, Kenneth M., Frederick E. Petry, Jack R. Adams-Webber, and Paul J. Chang. 1991. An Approach to Knowledge Acquisition Based on the Structure of Personal Construct Systems. IEEE Transactions on Knowledge and Data Engineering 3 (1): 78-88 (IEEE).

Fuchs-Kittowski, Frank, and Klaus Fuchs-Kittowski. 2007. Knowledge Management between Provision and Generation of Knowledge. In Knowledge Management: Innovation, Technology and Cultures, 165-175. World Scientific. Fujimura, J.H. 1987. Constructing 'Do-Able' Problems in Cancer Research: Articulating Alignment. Social Studies of Science 17 (2): 257-293 (Sage Publications).

Gasser, L. 1986. The Integration of Computing and Routine Work. ACM Transactions on Office Information Systems 4 (3): 205-225 (ACM Press).

Gerson, E.M., and Susan Leigh Star. 1986. Analyzing Due Process in the Workplace. ACM Transactions on Information Systems (TOIS) 4 (3): 257-270 (ACM Press).

Goguen, J. 1993. On Notation. Department of Computer Science and Engineering, University of California at San Diego.

Grice, H. Paul. 1969. Utterer's Meaning and Intention. The Philosophical Review 78 (2): 147-177 (JSTOR).

Groeben, N., and B. Scheele. 2000. Dialog-Konsens-Methodik im Forschungsprogramm Subjektive Theorien. Forum Qualitative Sozialforschung/Forum: Qualitative Social Research 1 (2). Deutschland.

Gross, Tom, Chris Stary, and Alex Totter. 2005. User-Centered Awareness in Computer-Supported Cooperative Work-Systems: Structured Embedding of Findings from Social Sciences. International Journal of Human-Computer Interaction 18 (3): 323-360 (Taylor \& Francis).

Grosskopf, A., J. Edelman, and Mathias Weske. 2010. Tangible Business Process Modeling-Methodology and Experiment Design. In Proceedings of Business Process Management Workshops (BPM 2009), pp. 489-500. 
Gruhn, Volker, Daniel Pieper, and Carsten Röttgers. 2007. $M D A^{\circledR}$ : Effektives Software-Engineering Mit UML2 ${ }^{\odot}$ Und EclipseTM. Springer-Verlag.

Hacker, Winfried. 1998. Allgemeine Arbeitspsychologie: Psychische Regulation Von Arbeitstätigkeiten. H. Huber.

Hahn, J., and J. Kim. 1999. Why Are Some Diagrams Easier to Work with? Effects of Diagrammatic Representation on the Cognitive Integration Process of Systems Analysis and Design. ACM Transactions on Computer-Human Interaction (TOCHI) 6 (3): 181-213 (New York: ACM Press).

Hampson, Ian, and Anne Junor. 2005. Invisible Work, Invisible Skills: Interactive Customer Service as Articulation Work. New Technology, Work \& Employment 20 (2): 166-181.

Harman, Joel, Ross Brown, Udo Kannengiesser, Nils Meyer, and Thomas Rothschädl. 2015. Model as You Do: Engaging an S-BPM Vendor on Process Modelling in 3D Virtual Worlds. In S-BPM in the Wild, ed. A. Fleischmann, W. Schmidt, and C. Stary, 113-133. Cham: Springer.

Hemmecke, J., and C. Stary. 2006. The Tacit Dimension of User Tasks: Elicitation and Contextual Representation. In International Workshop on Task Models and Diagrams for User Interface Design, 308-323. Berlin, Heidelberg: Springer.

Herrmann, Thomas, G. Kunau, K.U. Loser, and N. Menold. 2004. SocioTechnical Walkthrough: Designing Technology Along Work Processes. In Proceedings of the Eighth Conference on Participatory Design: Artful Integration: Interweaving Media, Materials and Practices, 132-141. New York: ACM Press. Herrmann, Thomas, M. Hoffmann, G. Kunau, and K.U. Loser. 2002. Modelling Cooperative Work: Chances and Risks of Structuring. In Proceedings of COOP 2002: Cooperative Systems Design, a Challenge of the Mobility Age, 53-70. IOS Press.

Himma, Kenneth Einar. 2009. Artificial Agency, Consciousness, and the Criteria for Moral Agency: What Properties Must an Artificial Agent Have to Be a Moral Agent? Ethics and Information Technology 11 (1): 19-29 (Springer). Holland, John H. 1992. Complex Adaptive Systems. Daedalus 121 (1): 17-30 (JSTOR).

- 2006. Studying Complex Adaptive Systems. Journal of Systems Science and Complexity 19 (1): 1-8 (Springer).

Hug, C., R. Deneckère, and C. Salinesi 2012, May. Map-TBS: Map Process Enactment Traces and Analysis. In 2012 Sixth International Conference on Research Challenges in Information Science (RCIS), 1-6. IEEE.

Hughes, F. 1971. The Sociological Eye. Aldine de Gruyter.

IEEE-Reliability Society Technical Committee on Systems of Systems. 2014. Systems of Systems Whitepaper. 
Ifenthaler, D. 2006. Diagnose Lernabhängiger Veränderung Mentaler ModelleEntwicklung Der SMD-Technologie Als Methodologisches Verfahren Zur Relationalen, Strukturellen Und Semantischen Analyse Individueller Modellkonstruktionen. University of Freiburg.

Jamshidi, Mo. 2008. System of Systems Engineering. Hoboken, NJ: John Wiley \& Sons, Inc.

Jaradat, Raed M, Charles B. Keating, and Joseph M. Bradley. 2014. A Histogram Analysis for System of Systems. International Journal of System of Systems Engineering 5 (3): 193-227 (Inderscience Publishers Ltd).

Jarvis, P. 2009. Learning to Be a Person in Society. Learning to Be Me. W:

K. Illeris (Red.), Contemporary Theories of Learning. Learning Theorists... in Their Own Words. London and New York: Routledge.

Jarvis, Peter, and Mary Watts. 2012. The Routledge International Handbook of Learning. Routledge.

Jensen Schau, Hope, and Mary C. Gilly. 2003. We Are What We Post? Self-

Presentation in Personal Web Space. Journal of Consumer Research 30 (3):

385-404 (The University of Chicago Press).

Johnson-Laird, P.N. 1981. Mental Models in Cognitive Science. Cognitive Science 4 (1): 71-115 (Elsevier).

Jørgensen, H.D. 2004. Interactive Process Models. PhD thesis, Department of Computer and Information Sciences, Norwegian University of Science and Technology Trondheim, Norway.

Kihlstrom, John F. 2013. The Person-Situation Interaction. In The Oxford Handbook of Social Cognition, ed. Donal E. Carlston, 768-805. Oxford: Oxford University Press.

Klein, G., B. Moon, and R.R. Hoffman. 2006. Making Sense of Sensemaking 1: Alternative Perspectives. IEEE Intelligent Systems 21 (4): 70-73 (IEEE Educational Activities Department, Piscataway, NJ).

Krogstie, J., Guttorm Sindre, and H.D. Jørgensen. 2006. Process Models Representing Knowledge for Action: A Revised Quality Framework. European Journal of Information Systems 15 (1): 91-102. https://doi.org/10.1057/ palgrave.ejis.3000598.

Kurzel, Frank, Jill Slay, and Kim Hagenus. 2003. Personalising the Learning

Environment. In Proceedings of Informing Science and Information Technology Education 2003 (InSITE).

Kyng, M. 1995. Making Representations Work. Communications of the ACM 38

(9): 46-55 (New York: ACM Press).

Lave, J. 1988. The Culture of Acquisition and the Practice of Understanding (Tech.

Rep. No. 88-0007). Palo Alto, CA: Institute for Research on Learning. 
Ludwig, H., Ch. Fischer, and R. Fischer. 2002. Montessori-Pädagogik in Deutschland. Rückblick-Aktualität_Zukunftsperspektiven: 40 Jahre Montessori-Vereinigung E.v. LIT Verlag.

Maier, M.W. (2005). Research Challenges for Systems-of-Systems. In 2005 IEEE International Conference on Systems, Man and Cybernetics, vol. 4, 31493154. IEEE.

Matheus, C.J., M.M. Kokar, K. Baclawski, and J.J. Letkowski. 2005, November. An Application of Semantic Web Technologies to Situation Awareness. In International Semantic Web Conference, 944-958. Berlin, Heidelberg: Springer.

Meyrowitz, Joshua. 1986. No Sense of Place: The Impact of Electronic Media on Social Behavior. Oxford University Press.

Millard, N., L. Hole, and S. Crowle. 1999, August. Smiling Through: Motivation at the User Interface. In Proceedings of HCI International (the 8th International Conference on Human-Computer Interaction) on Human-Computer Interaction: Ergonomics and User Interfaces-Volume I-Volume I, 824-828. L. Erlbaum Associates Inc. ISO 690.

Mirel, Barbara. 2004. Interaction Design for Complex Problem Solving: Developing Useful and Usable Software. Morgan Kaufmann.

Montague, Gerard P. 2013. Who Am I? Who Is She?: A Naturalistic, Holistic, Somatic Approach to Personal Identity. Walter de Gruyter.

Montessori, M. 2005. The Montessori Method. Kessinger Publishing.

Motschnig-Pitrik, R., and L. Nykl. 2001, July. The Role and Modeling of Context in a Cognitive Model of Rogers' Person-Centred Approach. In International and Interdisciplinary Conference on Modeling and Using Context, 275-289. Berlin, Heidelberg: Springer.

Neuweg, Georg Hans. 2004. Tacit Knowing and Implicit Learning. In European Perspectives on Learning at Work: The Acquisition of Work Process Knowledge, Cedefob Reference Series. Luxemburg: Office for Official Publications for the European Communities.

Nonaka, I., and H. Takeuchi. 1995. The Knowledge-Creating Company: How Japanese Companies Create the Dynamics of Innovation. Oxford University Press.

Norman, Donald A., and James C. Spohrer. 1996. Learner-Centered Education. Communications of the ACM 39 (4): 24-27.

Novak, Joseph D., and A.J. Canas. 2006. The Theory Underlying Concept Maps and How to Construct Them. Florida Institute for Human and Machine Cognition.

Oppl, Stefan. 2006. Towards Intuitive Work Modeling with a Tangible Collaboration Interface Approach. In Proceedings of WETICE '06, June. IEEE Press, 400-405. https://doi.org/10.1109/WETICE.2006.71. 
2016. Articulation of Work Process Models for Organizational Alignment and Informed Information System Design. Information \& Management 53 (5): 591-608. https://doi.org/10.1016/j.im.2016.01.004.

- 2017. Evaluation of Collaborative Modeling Processes for Knowledge Articulation and Alignment. Information Systems and E-Business Management 15 (3): 717-749 (Springer Berlin Heidelberg). https://doi.org/10.1007/ s10257-016-0324-9.

. 2018. Which Concepts Do Inexperienced Modelers Use to Model Work?-An Exploratory Study. In Proceedings of MKWI 2018.

Oppl, Stefan, and C. Stary. 2011a. Effects of a Tabletop Interface on the Co-Construction of Concept Maps. In Proceedings of the 13th IFIP TC13 Conference on Human-Computer Interaction (INTERACT 2011), 443-460. Berlin and Heidelberg: Springer. https://doi.org/10.1007/978-3-64223765-2_31.

. 2011b. Towards Informed Metaphor Selection for TUIs. In Proceedings of the 3rd ACM SIGCHI Symposium on Engineering Interactive Computing Systems (EICS 2011), ed. F. Paternò, 16-33 (Chap. 2). Communications in Computer and Information Science, vol. 213. Berlin and Heidelberg: ACM Press. https://doi.org/10.1007/978-3-642-23471-2_2.

- 2014. Facilitating Shared Understanding of Work Situations Using a Tangible Tabletop Interface. Behaviour \& Information Technology 33 (6): 619-635. https://doi.org/10.1080/0144929X.2013.833293.

Papert, Seymour. 1993. The Children's Machine: Rethinking School in the Age of the Computer. Basis Books.

Parsaye, Kamran, and Mark Chignell. 1988. Expert Systems for Experts. New York: Wiley.

Petrasch, R., and O. Meimberg. 2006. Model-Driven Architecture. Eine Praxisgerechte Einführung in Die MDA. Heidelberg: dpunkt.

Pirnay-Dummer, Pablo N. 2006. Expertise Und ModellbildungMITOCAR. University of Freiburg.

Polanyi, M. 1958. Personal Knowledge: Towards a Post-Critical Philosophy. Chicago: University of Chicago Press.

- 1966. The Tacit Dimension. Doubleday \& Co.

Pörtner, Marlis. 2008. Ernstnehmen-Zutrauen-Verstehen: Personzentrierte Haltung Im Umgang Mit Geistig Behinderten Und Pflegebedürftigen Menschen. Klett-Cotta.

Resnick, Mitchel, Amy Bruckman, and Fred Martin. 1996. Pianos Not Stereos: Creating Computational Construction Kits. Interactions 3 (5): 40-50 (ACM). 
Robinson, Laura. 2007. The Cyberself: The Self-Ing Project Goes Online, Symbolic Interaction in the Digital Age. New Media \& Society 9 (1): 93-110 (Thousand Oaks, CA: Sage Publications).

Rogers, Carl R. 1951. Client-Centered Therapy: Its Current Practice, Implications, and Theory. Boston, MA: Houghton Mifflin.

- 1961. On Becoming a Person: A Therapist's Point of View of Psychotherapy. Alemar.

Rolland, Colette, Naveen Prakash, and Adolphe Benjamen. 1999. A MultiModel View of Process Modelling. Requirements Engineering 4 (4): 169-187 (Springer).

Roussos, Maria, Andrew E. Johnson, Jason Leigh, Christina A. Vasilakis, Craig R. Barnes, and Thomas G. Moher. 1997. NICE: Combining Constructionism, Narrative and Collaboration in a Virtual Learning Environment. Computer Graphics-New York-Association for Computing Machinery 31: 62-63 (ACM Association for Computing Machinery).

Rubin, David C. 2006. The Basic-Systems Model of Episodic Memory. Perspectives on Psychological Science 1 (4): 277-311 (Los Angeles, CA: SAGE Publications).

Ruiz-Primo, M.A., and R.J. Shavelson. 1996. Problems and Issues in the Use of Concept Maps in Science Assessment. Journal of Research in Science Teaching 33 (6): 569-600.

Russell, D.M., M.J. Stefik, P. Pirolli, and S.K. Card. 1993. The Cost Structure of Sensemaking. In Proceedings of the SIGCHI Conference on Human Factors in Computing Systems. New York, pp. 269-276.

Sachs, Patricia. 1995. Transforming Work: Collaboration, Learning, and Design. Communications of the ACM 38 (9): 36-44 (New York: ACM Press).

Scheer, August Wilhelm. 2003. ARIS_Business Process Modeling. 3rd ed. Springer.

Schön, D. 1984. The Reflective Practitioner: How Professionals Think in Action. Basic Books.

Schön, Donald A. 1987. Educating the Reflective Practitioner. San Francisco: Jossey-Bass.

Seel, Norbert M. 2003. Model-Centered Learning and Instruction. Technology, Instruction, Cognition and Learning 1 (1): 59-85 (Old City Publishing).

Senge, P.M. 1990. The Fifth Discipline: The Art and Practice of the Learning Organization. Doubleday/Currency.

Senge, Peter M., and John D. Sterman. 1992. Systems Thinking and Organizational Learning: Acting Locally and Thinking Globally in the 
Organization of the Future. European Journal of Operational Research 59 (1): 137-150 (Elsevier).

Sheeran, Paschal. 2002. Intention-Behavior Relations: A Conceptual and Empirical Review. European Review of Social Psychology 12 (1): 1-36 (Taylor \& Francis).

Spindler, M., and Christian Stary. 2017. SoS: Anarchy Active Inner Spacing for Co-Creating Future Outer Space. Challenging Organisations and Society 6 (1): 1013-1054.

Stary, C., and D. Wachholder. 2016. System-of-Systems Support-A Bigraph Approach to Interoperability and Emergent Behavior. Data \& Knowledge Engineering 105: 155-172.

Stary, Christian. 2000. TADEUS: Seamless Development of Task-Based and User-Oriented Interfaces. IEEE Transactions on Systems, Man, and CyberneticsPart A: Systems and Humans 30 (5): 509-525 (IEEE).

- 2014. Non-Disruptive Knowledge and Business Processing in Knowledge Life Cycles-Aligning Value Network Analysis to Process Management. Journal of Knowledge Management 18 (4): 651-686 (Emerald Group Publishing Limited).

- 2017a. Interactive Articulation and Probing of Processes: Capturing Intention and Outcome for Coherent Workplace Design. In The Future Information Society: Social and Technological Problems, 241-257. World Scientific.

- 2017b. Requirements Elicitation and Specification Using the S-BPM Paradigm. REFSQ Workshops Proceedings, Workshop on Continuous Requirements Engineering, 1796.

- 2017c. System-of-Systems Design Thinking on Behavior. Systems 5 (1): 3 (Multidisciplinary Digital Publishing Institute).

- 2017d. Walking on 2 Legs: 3D-Structured Method Alignment in

Project Management. In Interactivity, Game Creation, Design, Learning, and Innovation, 33-42. Springer.

Sternberg, Robert J., Joseph A. Horvath, and others. 1999. Tacit Knowledge in Professional Practice: Researcher and Practitioner Perspectives. Psychology Press. Strauss, A. 1985. Work and the Division of Labor. The Sociological Quarterly 26 (1): 1-19 (Blackwell Publishing Ltd).

- 1988. The Articulation of Project Work: An Organizational Process. The Sociological Quarterly 29 (2): 163-178.

-1993. Continual Permutations of Action. New York: Aldine de Gruyter. Subramanya, S.R., and Byung K. Yi. 2007. Enhancing the User Experience in Mobile Phones. IEEE Computer 40 (12): 114-117. 
Suchman, L. 1995. Making Work Visible. Communications of the ACM 38 (9): 56-64 (New York: ACM Press).

Turkle, Sh. 1998. Leben Im Netz. Identitäten in Zeiten Des Internet. Reinbeck bei Hamburg: Rowohlt.

Ulich, E. 1994. Arbeitspsychologie. 4., Überarbeitete Und Erweiterte Auflage, 1998. Stuttgart: Schäffer-Poeschel.

Waddock, Sandra, Greta M. Meszoely, Steve Waddell, and Domenico Dentoni. 2015. The Complexity of Wicked Problems in Large Scale Change. Journal of Organizational Change Management 28 (6): 993-1012 (Emerald Group Publishing Limited).

Weichhart, Georg, Christian Stary, and François Vernadat. 2018. Enterprise Modelling for Interoperable and Knowledge-Based Enterprises. International Journal of Production Research 56 (8): 2818-2840 (Taylor \& Francis).

Weiser, M. 1991. The Computer for the 21st Century. Scientific American 265: 94-104.

Weske, Mathias. 2010. Business Process Management: Concepts, Languages, Architectures. Springer.

Zuckerman, Oren, S. Arida, and M. Resnick. 2005. Extending Tangible Interfaces for Education: Digital Montessori-Inspired Manipulatives. In Proceedings of the SIGCHI Conference on Human Factors in Computing Systems (CHI), 859-868. New York: ACM Press.

Open Access This chapter is licensed under the terms of the Creative Commons Attribution 4.0 International License (http://creativecommons.org/licenses/ by/4.0/), which permits use, sharing, adaptation, distribution and reproduction in any medium or format, as long as you give appropriate credit to the original author(s) and the source, provide a link to the Creative Commons licence and indicate if changes were made.

The images or other third party material in this chapter are included in the chapter's Creative Commons licence, unless indicated otherwise in a credit line to the material. If material is not included in the chapter's Creative Commons licence and your intended use is not permitted by statutory regulation or exceeds the permitted use, you will need to obtain permission directly from the copyright holder.

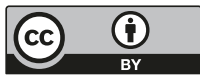

